\title{
Thrombin: An Approach to Developing a Higher-Order Reference Material and Reference Measurement Procedure for Substance Identity, Amount, and Biological Activities
}

\author{
Craig M. Jackson ${ }^{1}$, M. Peter Esnouf ${ }^{2}$, and David L. Duewer ${ }^{3}$ \\ ${ }^{15} 5931$ Seacrest View Road \\ San Diego, CA 92121-4355, USA \\ 27 Stonesfield Road \\ Combe, Witney, OX29 8PF, UK \\ ${ }^{3}$ National Institute of Standards and Technology, \\ Gaithersburg, MD 20899-8390, USA
}

CraigMJacksonSD@outlook.com

peter.esnouf@ndcls.ox.ac.uk

david.duewer@nist.gov

\begin{abstract}
Thrombin, the proteolytic enzyme that catalyzes the transformation of soluble fibrinogen to the polymerized fibrin clot, participates in multiple reactions in blood coagulation in addition to the clotting reaction. Although reference materials have existed for many years, structural characterization and measurement of biological activity have never been sufficient to permit claims of clear metrological traceability for the thrombin preparations. Our current state-of-the-art methods for protein characterization and determination of the catalytic properties of thrombin now make it practical to develop and characterize a metrologically acceptable reference material and reference measurement procedure for thrombin. Specifically, $\alpha$-thrombin, the biologically produced protease formed during prothrombin activation, is readily available and has been extensively characterized. Dependences of thrombin proteolytic and peptide hydrolytic activities on a variety of substrates, $\mathrm{pH}$, specific ions, and temperature are established, although variability remains for the kinetic parameters that describe thrombin enzymatic action. The roles of specific areas on the surface of the thrombin molecule (exosites) in substrate recognition and catalytic efficiency are described and characterized. It is opportune to develop reference materials of high metrological order and technical feasibility. In this article, we review the properties of $\alpha$-thrombin important for its preparation and suggest an approach suitable for producing a reference material and a reference measurement procedure that is sensitive to thrombin's catalytic competency on a variety of substrates.
\end{abstract}

Key words: blood clotting; clotting activity; exosite; fibrinogen; fibrinopeptide; heparin; peptide p-nitroanilide; thrombin; $\alpha$-thrombin; $\beta$-thrombin; $\gamma$-thrombin.

Accepted: June 30, 2020

Published: July 29, 2020

https://doi.org/10.6028/jres.125.021 


\section{Glossary}

1PPB Protein Data Bank designation for thrombin (human coordinates from X-ray structure)

1TRN Protein Data Bank designation for trypsin (human)

Arg arginine

Factor II prothrombin, sometimes simply designated "Pro" in coagulation literature

Factor V

precursor of the nonenzymatic catalyst factor $\mathrm{Va}$, a component of prothrombinase, the complex activator that converts prothrombin to thrombin. Cleavage of factor $\mathrm{V}$ to form factor $\mathrm{Va}$ is catalyzed by thrombin and less efficiently by factor Xa

Factor Va see factor $\mathrm{V}$

Factor VIIa protease catalyzing cleavage of factor $\mathrm{X}$ to form factor $\mathrm{Xa}$, the protease that cleaves prothrombin. Factor VII is the first protease precursor of the "extrinsic pathway" of coagulation

Factor VIII the antihemophilic factor (hemophilia A) that, after activation, participates catalytically in the activation of factor X. Thrombin cleaves factor VIII to form factor VIIIa

Factor IX precursor of the protease that catalyzes the cleavage of factor X in the "intrinsic pathway" of coagulation

Factor IXa protease catalyzing cleavage of factor X

Factor $\mathrm{X}$ precursor of the protease that cleaves prothrombin to produce thrombin

Factor Xa a component of the protease prothrombinase that cleaves prothrombin

Factor XI precursor of the protease that cleaves factor IX to form factor IXa

Factor XIa activates factor IX

Factor XIII precursor to the plasma transglutaminase factor XIIIa that crosslinks fibrin, which prevents its rapid dissociation by dilution from blood flow. Thrombin catalyzes formation of factor XIIIa

Factor XIIIa enzymatically active transglutaminase

$\mathrm{F}_{\mathrm{m}} \quad$ fibrin monomer

Gene $\mathrm{F}(*) \quad$ genes are named similar to the coagulation factors, but substituting the Arabic numeral for the Roman numeral

Gly glycine

FpA fibrinopeptide A

FpB fibrinopeptide B

His histidine

$\mathrm{k}_{\mathrm{c}} \quad$ catalytic constant of the Michaelis-Menten description of the kinetics of enzyme action

$\mathrm{K}_{\mathrm{m}} \quad$ Michaelis constant, describing the kinetic constants for the association of substrate with enzyme

Lys lysine

PARs protease-activated receptors

Phe phenylalanine

Pip piperidine

pNA p-nitroaniline

Protein $\mathrm{C}$ the vitamin $\mathrm{K}$-dependent protease precursor of the enzyme, protein $\mathrm{Ca}$

Protein $\mathrm{Ca}$ Activated protein $\mathrm{C}$ or PCa is the inactivation of factors Va and VIIIa

TAFI Thrombin-activated fibrinolysis inhibitor

Tosyl p-toluene sulfonyl 


\section{Introduction}

Understanding the challenge of developing a reference material and reference measurement procedures for both substance amount and quantification of biological activity for thrombin is a prerequisite to an appropriate reference system for this biological material. More specifically, a system suitable for the intended uses of the material and procedure must include clear definition of the identity of the substance as determined by its structure and its structure-determined biological activities.

Identification of the structure-function relationships that are documented for thrombin is facilitated by a brief description of the biological system in which thrombin participates and in which it is produced, i.e., a description of the biological context of thrombin. Because thrombin, initially called "fibrin ferment," was first postulated to be the agent causing the transformation of flowing blood into a gel in 1872 [1], an account of some of the legacy of prior approaches to developing reference materials for thrombin biological activity assessment is helpful. This discussion is intended to enable the previously encountered impediments to a metrology-based reference system for thrombin to be avoided.

The production of thrombin, as a substance rather than an "activity" capable of initiating clot formation, was first achieved in the late 1930s [2]. A commercial product employed to stop bleeding, "Thrombin, Topical," was developed by Parke, Davis and Company and used in both clinical and research applications. Identification of other coagulation factor activities in "Thrombin, Topical" $[3,4]$ and its somewhat unsatisfactory physical appearance (turbid, gray, and with evident particulates) occurred as technology advanced. The development of large-scale purification of thrombin from Cohn fraction III [5] led to better and, in many cases, highly active and apparently homogeneous preparations that were stable and widely usable as a reference material for measuring thrombin activity [6]. Continuing until today, thrombin "standards," sponsored by the World Health Organization (WHO) and U.S. National Institutes of Health (NIH), provide the basis for measurement of thrombin biological activity [7]. However, characterization of these thrombin reference materials has been limited and not focused on substance homogeneity, amount, or biological activity as necessarily linked properties. The goal of this document is to outline an approach that can meet metrological criteria for traceability and serve as a guide to developing a higher-order reference material for both substance amount and biological activity; the proposed approach is illustrated as a traceability path in Fig. 1.

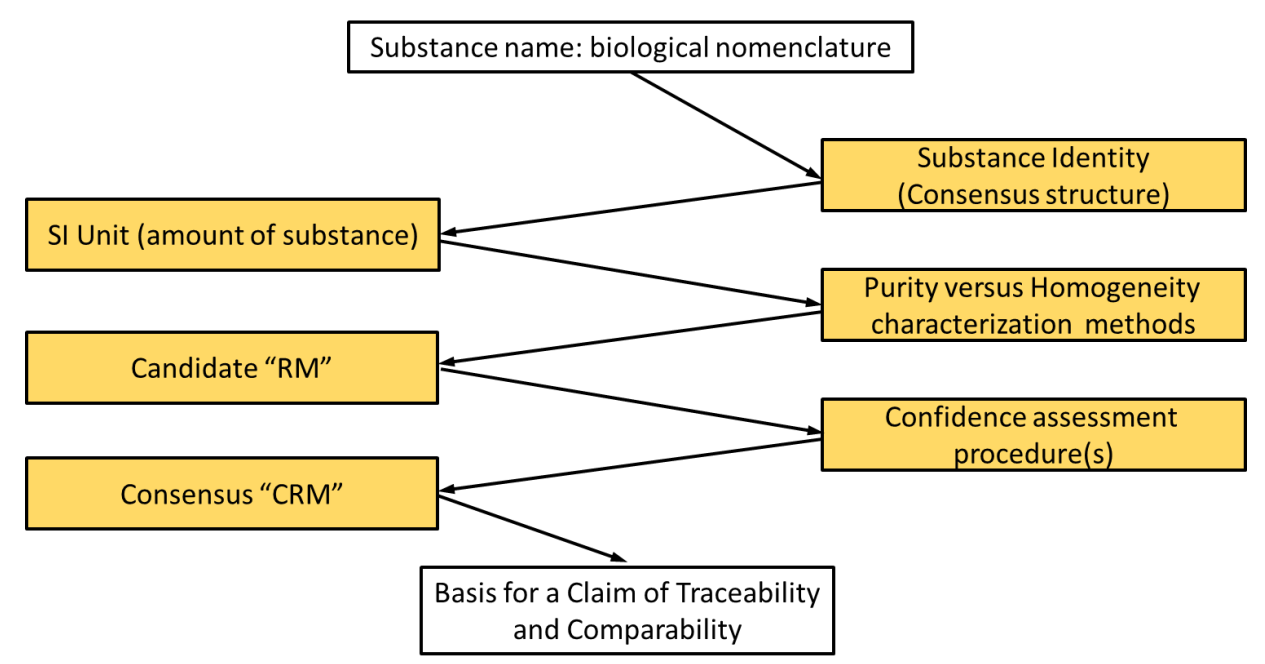

Fig. 1. A modified traceability path for macromolecules of biological origin. Consensus on the structure that will define the macromolecule is required because of the inherent heterogeneity that exists because of genetic sequence and posttranslational polymorphisms. Historical names are maintained for recognitions of the substance, but the agreed amino sequence, after acceptance, becomes the defining structure. An "RM" is a reference material in which the measurand is known to be fit-or-purpose homogenous and stable but for which the true value of the measurand has not been sufficiently well-established. A "CRM" is a certified RM for which an interval containing the true value of the measurand has been established with a stated level of confidence. 


\section{Thrombin}

A voluminous body of literature for thrombin exists; more than 48,000 publications are listed in Medline, and about 450 crystallographic structures are reported in the Protein Data Bank [8], wherein many structures are of thrombin-drug and thrombin-inhibitor complexes. If a defensible consensus structure for thrombin is to be decided, candidates must be comprehensively evaluated with respect to the structural information that exists in the literature and the functional consequences of differences in structure. Thus, a focused, although necessarily limited, review of the structural and functional properties of thrombin needs to be made prior to proposing a reference structure for a highest-order reference material. An inappropriate choice of sequence could have unintended adverse consequences by introducing bias in the proposed reference measurement procedure. Inappropriate in this context is taken to mean that sequence variants (mutations) known to affect structure (tertiary or quaternary) and/or any of thrombin's biological function should be excluded.

Recombinant thrombin can be produced based on the consensus sequence $[9,10,11]$, but it would be expensive compared to that from human plasma. Fortunately, naturally occurring mutations with functional impairment are rare in thrombin, thus making them unlikely to affect the protein isolated from human plasma. Residues within the thrombin sequence have been identified as functionally important from study of those rare mutations and from recombinant thrombins in which residues have been replaced by site-directed mutagenesis. Screening for the presence of significant amounts of such undesirable residues in the sequence can be done, and any pools of plasma with a high prevalence of them can be excluded or reduced to inconsequential prevalence using contemporary technologies such as protein mass spectroscopy (MS). Inconsequential can be interpreted to mean within the measurement uncertainty for the analytical procedure.

\subsection{Substance Identity, Name versus Biochemical Entity}

As the first step to developing a thrombin reference material that is metrologically traceable, the explicit primary structure that will identify the substance "thrombin" (specifically, $\alpha$-thrombin ${ }^{1}$ ) must be decided. Because of the inherent, although limited, amino acid sequence heterogeneity of proteins of biological origin, the amino acid sequence for "the reference thrombin" must be decided by consensus. A proposed sequence will be suggested that addresses the heterogeneity in a way that is both practical and that identifies the preparation of thrombin explicitly but allows for new discoveries of structure-function relationships for thrombin to be considered and included in the proposed reference system. If possible (economically), the actual sequence of the protein preparation with heterogeneities in sequence could be determined.

The purity of the thrombin preparation must be established. It is worth noting, however, that purity of preparations of macromolecules, and the evidence used to claim minimal heterogeneity, was first recognized as the result of a process of exclusion, rather than by properties that can be used with simple substances. This was presciently stated in 1940 [12]: “...purity is a concept that has no meaning except with reference to the methods and assumptions used in studying the substance..." More explicitly, the fidelity of the material chosen to represent the sequence selected to identify the substance thrombin depends on the sensitivity and selectivity of the analytical methods employed to detect contaminants (impurities) and the number of different properties characterized. By this approach, metrological confidence can be established, and the acceptability of the resulting thrombin preparation as the highest-order reference material can be judged suitable for its intended uses.

\footnotetext{
${ }^{1}$ Unless stated otherwise, thrombin implies $\alpha$-thrombin, the physiologically relevant and fully competent proteolytic enzyme that converts fibrinogen to fibrin.
} 


\subsection{Biochemical and Structural Context}

Thrombin is a member of the serine protease family (EC 3.21.5), the group of enzymes in which chymotrypsin and trypsin are the classical reference enzymes [13]. Although initially categorized based on the "charge-relay" mechanism of action, amino acid sequences showed that trypsin and chymotrypsin are structurally homologous proteins [14]. After completion of the amino acid sequence for bovine thrombin, it was evident that thrombin is homologous in the underlying scaffold to these proteases. Notable differences were observed; in particular, insertions were found in the thrombin sequence. These insertions were commonly at locations predicted to be on the surface of the thrombin molecule $[15,16]$. When the three-dimensional structure of thrombin was reported, it was clear that the inserted regions were in fact on the surface of the thrombin molecule, offering plausible explanations for differences in specificity toward protein substrates between thrombin and trypsin.

Prior to the three-dimensional structure for thrombin, many investigators compared thrombin with trypsin, focusing on the notable similarities [17]; however, other investigators focused on the differences between thrombin and trypsin and began investigating the possible functional significance of these additional surface residues. An early proposal was that the surface residues might create exosites, i.e., sites distinct and remote from the catalytic or active site of thrombin $[18,19]$. Exosites quickly came to be the focus of investigations directed to describing and differentiating among the interactions between thrombin and its many protein substrates [20]. Ribbon diagrams for trypsin and thrombin (see Fig. 2) illustrate both the similarities and differences between these two proteolytic enzymes.

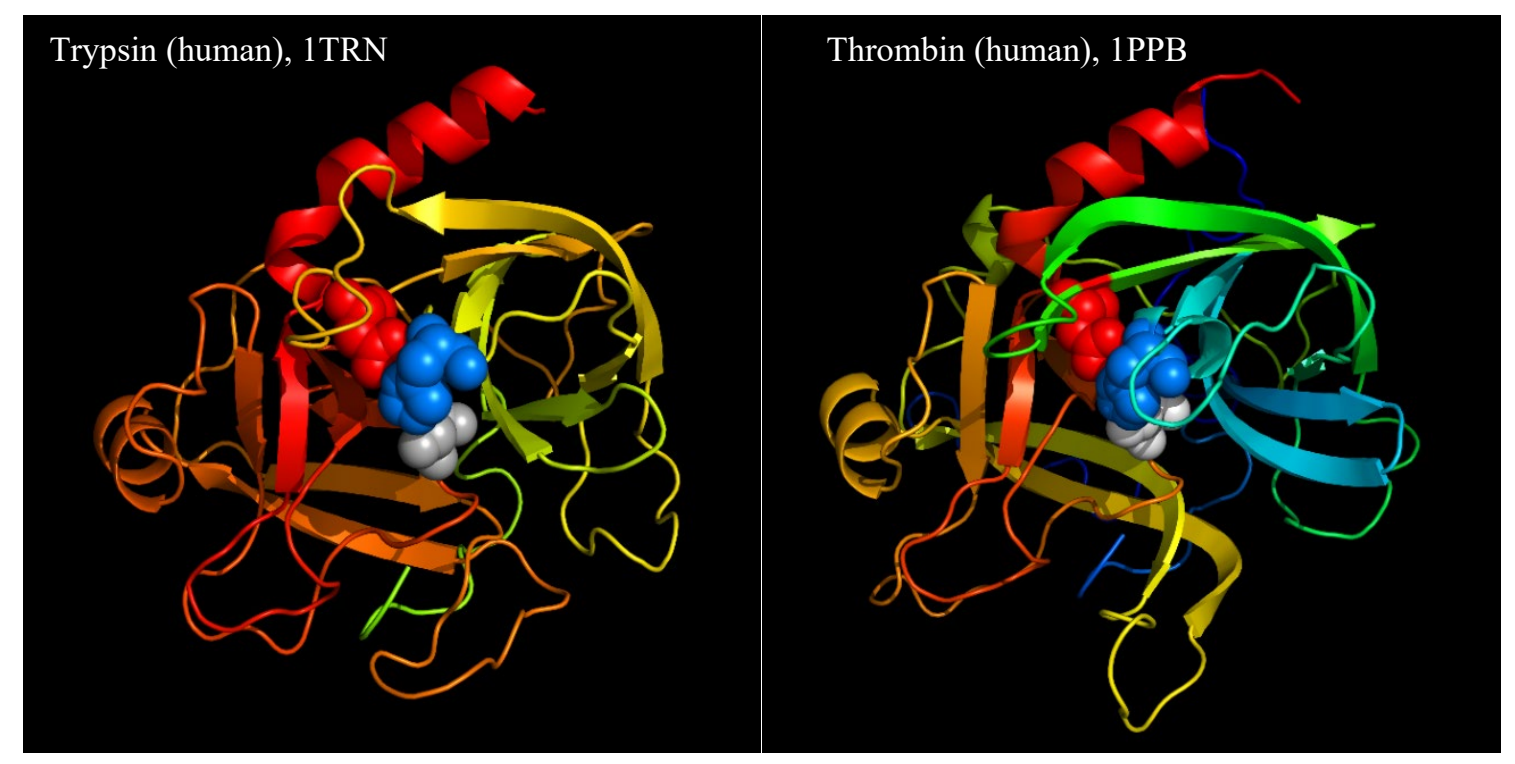

Fig. 2. Trypsin versus thrombin — related proteases with property-related differences. Comparison of thrombin with the more widely recognized protease trypsin facilitates identification of the functional differences in thrombin that result from the insertions of amino acid sequences that create regulatory sites on thrombin. Trypsin can proteolytically cleave all arginyl and lysyl peptide bonds in proteins; thrombin is primarily directed to arginyl residues on its protein substrates, partly determined by accessibility and partly by the expanded active site region in thrombin. Trypsin structure 1TRN is from Ref. [21]; thrombin structure 1PPB is from Ref. [22]. All molecular structures in this report were created with PyMOL, an open-source molecular visualization system (https://en.wikipedia.org/wiki/PyMOL). 


\subsection{Primary, Secondary, and Tertiary Structures}

It is proposed that the "defining" primary structure of thrombin given in the UniProt database [23], a highly curated protein structure database, be established as the consensus amino acid sequence for human $\alpha$-thrombin (Fig. 3). The sequence is derived from both protein and complementary deoxyribonucleic acid (cDNA) sequences [24, 25]. Subsequent differences in residues are found in X-ray crystallographic structures, documented in the Protein Data Bank files [8]. Tables of sequence conflicts and naturally occurring variants are given in the UniProt database, http://www.uniprot.org/uniprot/P00734\#sequences. Limited numbers of residues with sequence conflicts and residues shown by site-directed mutagenesis to be important are shown in Fig. 4.

Thrombin light chain (Residues: 328-363) - Molecular weight: 4,090.5 TFGSGEADCGLRPLFEKKSLEDKTERELLESYIDGR

Thrombin heavy chain (Residues: 364-622) - Molecular weight: 29,276.7 IVEGS DAEI GMS PWQVMLFRKSPQELLCGASL ISDRWVLTAAHCLLYPPWDKNFTENDLL VRIGKHSRTRYERNIEKISMLEKIYIHPRYNWRENLDRDIALMKLKKPVAFSDYIHPVCL PDRETAASLLQAGYKGRVTGWGNLKETWTANVGKGGQPSVLQVVNLPIVERPVCKDSTRIR ITDNMFCAGYKPDEGKRGDACEGDSGGPFVMKSP FNNRWYQMGIVSWGEGCDRDGKYGFY (603) THVFRLKKWIQKVIDQFGE (622)

Oligosaccharide chain - Molecular weight: 2,368.8 $\quad \alpha$-Thrombin - Molecular weight: 35,736

Fig. 3. Amino acid sequence of thrombin, showing catalytic triad and inserted sequences. The inserted sequences suggested in Refs. [16, $26,27]$ are underlined to illustrate the structural differences from trypsin that are responsible for the specificity exhibited by thrombin for the multiple protein substrates on which it acts. Catalytic site residues, $H, D, S$, are marked in red; the $N$ of the oligosaccharide chain attachment is in green; half-cysteine residues, $C$, are in yellow. The sequence and molecular weights are from UniProt P000734.

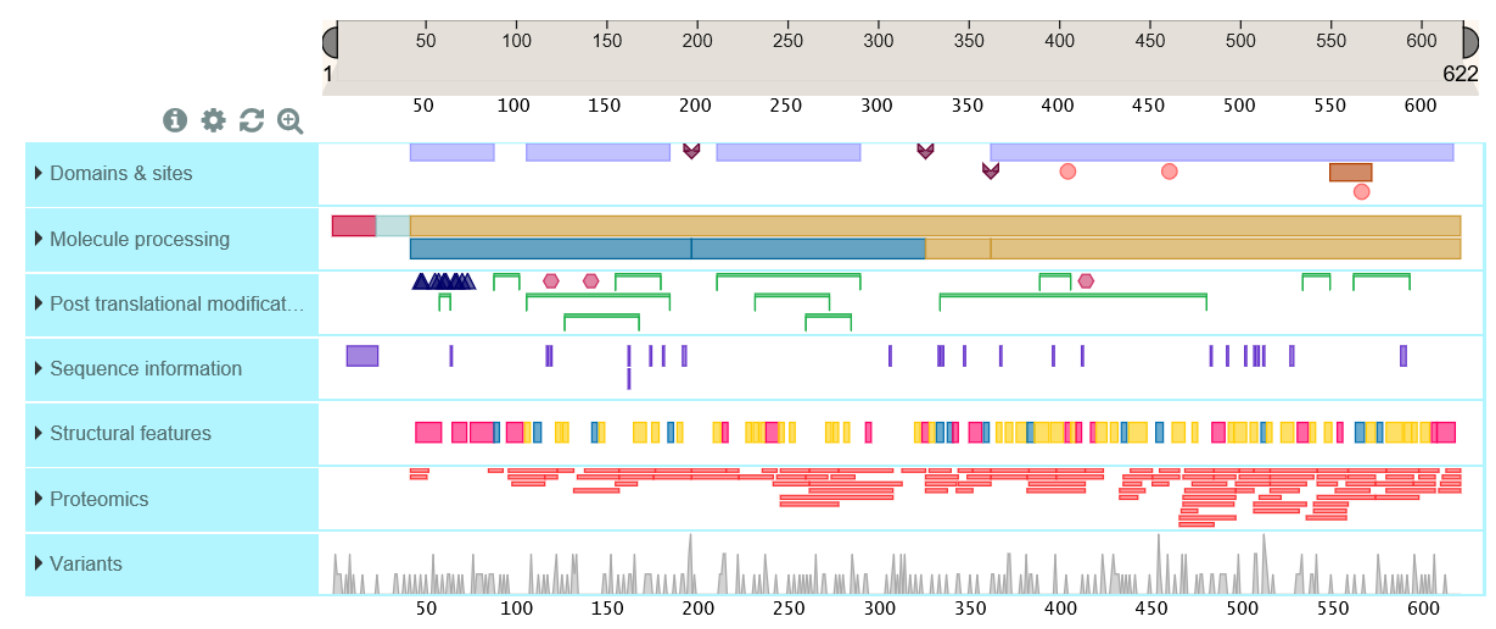

Fig. 4. UniProtKB, a most useful source for structural information for proteins. UniProtKB (KnowledgeBase) is a curated, hierarchically organized database that provides extensive structural and brief functional information for proteins. 
Structural features revealed in the three-dimensional structure of thrombin underlie many of the functional attributes that confer the specificity that thrombin exhibits toward protein substrates. Figure 5 shows an annotated three-dimensional structure derived from the Protein Databank Entry, 1PPB, the first reported structure for human thrombin $[22,28]$.

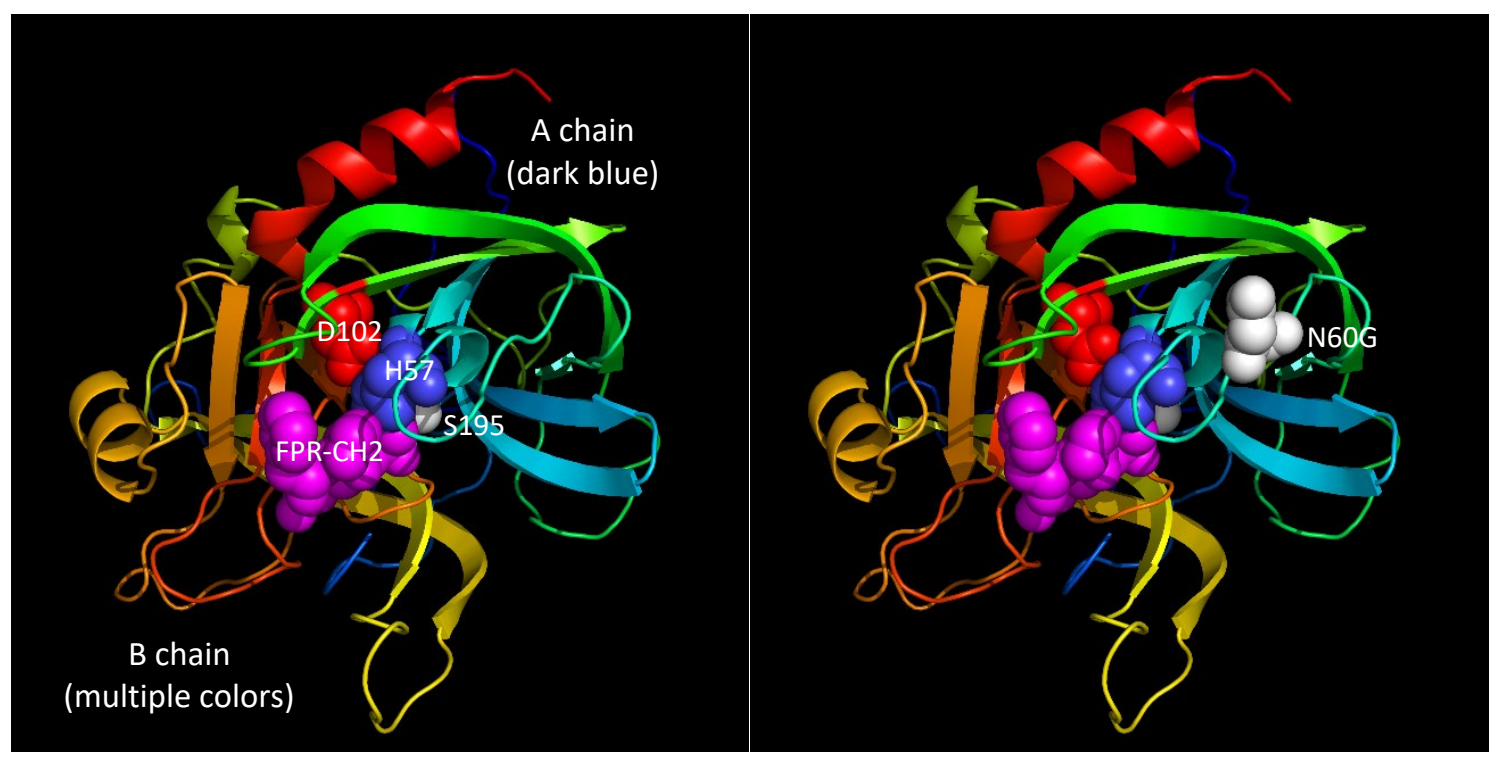

Fig. 5. Thrombin, showing the catalytic triad and the location of the single oligosaccharide chain. The catalytic triad, serine 195 (S195), histidine 57 (H57), and aspartate 102 (D102), are the residues that are directly responsible for the proteolytic activity of serine proteases. An oligosaccharide chain is attached to asparagine, N60G. (Numbering is that first reported for chymotrypsin to facilitate identification on three-dimensional structures because crystallographers employ this system. The Appendix cross-references the several thrombin numbering systems used in the literature.) The Phe-Pro-Arg- $\mathrm{CH}_{2}$ residue $\left(\mathrm{FPR}-\mathrm{CH}_{2}\right)$ is a covalent inhibitor that has reacted with $\mathrm{H} 57$ to provide a proteolytically inactive thrombin that can be crystallized. This sequence is from UniProt P000734.

\subsection{Exosites-Distinguishing Structural Features of Thrombin and Other Coagulation Proteases}

Exosites (protein ligand binding sites), composed of residues identifiable at or near the surface of the thrombin molecule, provide for the special interactions between thrombin and protein substrates [20]. Ligands, when bound at these sites, alter the specificity and catalytic efficiency of thrombin. The first clear indication of the importance of an exosite arose from the interaction of thrombin with the polypeptide hirudin ( 65 amino acid residues) from the leach Hirudo medicinalis [29, 30]. Hirudin has been studied extensively because of its ability to prevent blood from clotting [31,32]. Hirudin's very tight binding to thrombin suggested interactions beyond the active site; this was confirmed by the publication of the three-dimensional structure of the thrombin-hirudin complex [33, 34] and direct binding measurements [31, 35, 36]. Portions of the hirudin molecule block access to the active site; however, most of the hirudin is folded around a groove in the surface of thrombin away from the active site [37,38]. Interaction between the hirudin "tail" and the residues away from the active site operationally defines the exosite, subsequently designated exosite 1 . Several other proteins bind to thrombin at exosite 1, each with distinguishable effects on thrombin's specificity [39, 40, 42].

Evidence that heparin formed a ternary complex between thrombin and the inhibitor antithrombin during the heparin-catalyzed inactivation of thrombin by antithrombin implied another exosite on thrombin [41, 42]. This interaction site on thrombin, now known as "exosite 2," is not limited to interacting with heparin and other glycosaminoglycans, but proteins as well. One interaction with exosite 2 involves binding of one of the activation fragments (prothrombin fragment 2) [43]. This fragment and the complete "pro-half" of prothrombin are produced during prothrombin conversion to thrombin. This interaction is involved in the prothrombinase- 
catalyzed activation of prothrombin $[44,45]$ and has been observed crystallographically [75] to alter thrombin action on a model protein substrate [46]. The structural integrity and the absence of substances that interact with thrombin exosites are important considerations regarding the purity of a thrombin reference material.

Exosites and amino acid residues in portions of the thrombin polypeptide chain adjacent to the active site have been investigated by site-directed mutagenesis, evaluating the contributions of these residues to thrombin specificity toward protein substrates. Although not identified as naturally occurring variants, differences in these residues are undesirable in a reference material but are unlikely to be present in thrombin produced from prothrombin isolated from blood of individuals with no bleeding disorders. These structural features, e.g., exosites and functionally important residues, are shown in Figs. 6-8.

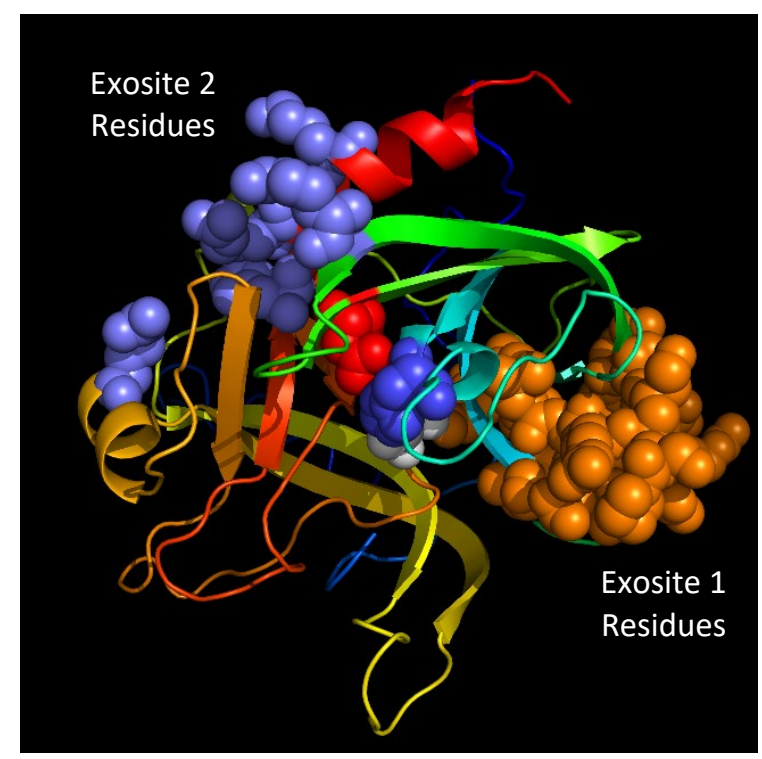

Fig. 6. Exosites on the thrombin surface-determinants of thrombin specificity. Exosites 1 and 2 are created from the inserted amino acid sequences (Figs. 2 and 3) and are responsible for the recognition sites for thrombin's many macromolecular substrates, its inhibitors, and the glycosaminoglycan, heparin. Residues implicated in the exosites are from Ref. [47].

\subsection{Thrombin $\mathrm{Na}^{+}$Binding Site-Specific Ion-Directed Substrate Specificity}

Thrombin possesses a binding site for a single sodium ion that alters thrombin specificity for its substrates $[48,49]$. When the $\mathrm{Na}^{+}$site is fully occupied, thrombin specificity and catalytic efficiency are preferentially directed to fibrinogen as the substrate. When unoccupied, the specificity is directed to protein C, i.e., the proteinase that functions in stopping the conversion of prothrombin to thrombin by proteolytically inactivating a component (factor $\mathrm{Va}$ ) of the prothrombin activation complex (prothrombinase) [50, 51]. Figure 7 shows the residues identified as forming the $\mathrm{Na}^{+}$site $[52,53]$. While unlikely to be an influence quantity in a reference measurement procedure, mutations in this site are undesirable for a reference material. 


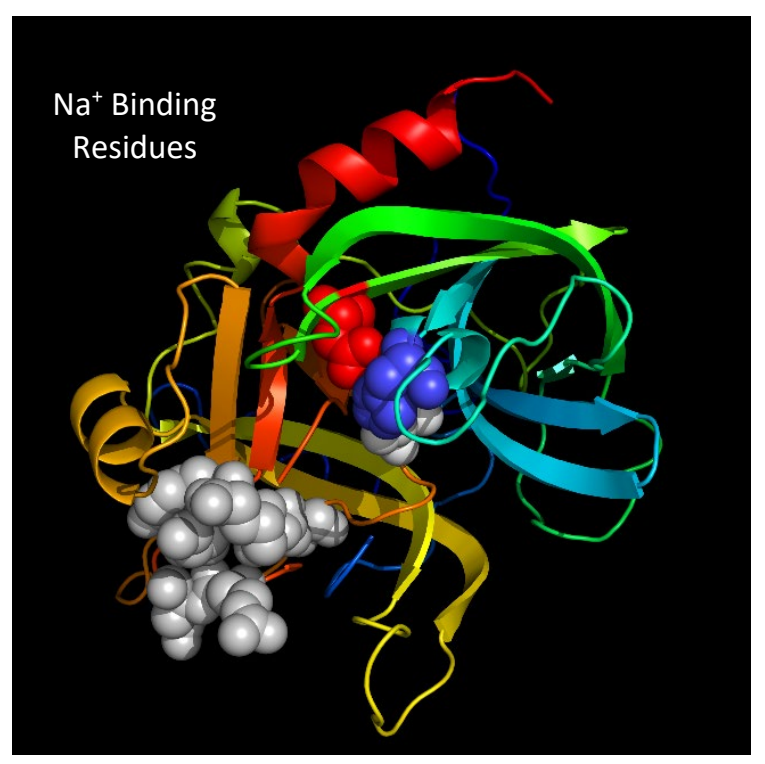

Fig. 7. The $\mathrm{Na}^{+}$binding site of thrombin. Two conformers of thrombin exist, a "fast form," which is the most efficient conformation for cleavage of the fibrinopeptides from fibrinogen, and a "slow form," which is the most efficient conformation for activation of protein C when in complex with the cofactor protein thrombomodulin. The "fast form" favors clotting; the "slow form" participates in reactions that shut off thrombin formation. The $\mathrm{Na}^{+}$site is fully occupied in the "fast form"; it is unoccupied in the "slow form." Residue identification is from Refs. [81, 86].

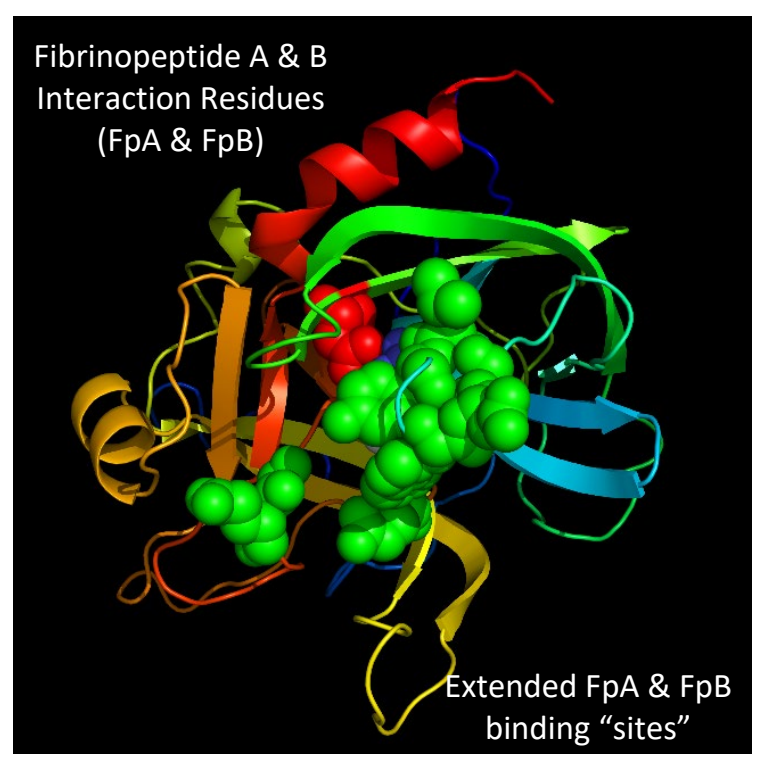

Fig. 8. The expanded active site of thrombin. Restriction of thrombin action on its protein substrates is determined by its expanded active site. Shown here are residues related to binding the fibrinopeptides as determined by crystallography of a fibrinopeptide-thrombin complex $[51,54,55]$. 


\subsection{Importance of Mutations and Polymorphisms: Effects on Thrombin Biological Activity}

Primary structure variants can be classified as "silent or inconsequential," i.e., without detectable effect on the biological activity in the reference measurement procedure, or "consequential," i.e., with demonstrable effect on the biological activity, i.e., on substrate recognition and proteolytic cleavage efficiency.

Because thrombin is widely recognized as the protease responsible for the conversion of fibrinogen, the soluble protein that circulates in the blood plasma, into the gelatinous fibrin blood clot, this makes fibrinogen an attractive choice for the substrate for a reference measurement procedure. However, fibrinogen is only one of thrombin's substrates of physiological and medical importance in blood clotting. Consideration of other substrates is necessary prior to making the selection. Thrombin participates in more than six different proteolytic reactions in blood coagulation prior to clot formation [56, 57], and it interacts with cell receptors that do not require proteolysis for response $[46,58,59]$.

An important discovery related to thrombin involvement in multiple reactions is that its specificity with respect to its action on protein substrates and cell receptors involves interaction between thrombin and several other plasma proteins. Moreover, only some of these interactions are classical enzyme-substrate interactions; other interactions involve the proteins as effector (regulatory) molecules that alter the catalytic specificity and efficiency of thrombin. From a purely biological knowledge perspective, the multiplicity of interactions of other proteins with thrombin represents a fascinating set of regulatory processes to investigate and to understand. However, from the perspective of development of a reference system for measuring thrombin activity and substance amount, such interacting molecules fall more obviously into the category of influence quantities. Consequently, effects of these proteins on the measurement of thrombin activity should be minimized, and the knowledge regarding them should be used to guide the development of the measurement methods and materials. Some of these influence quantities probably cannot be eliminated entirely from routine methods, but their effects should be minimized in those procedures.

As will be described below, a reference measurement procedure based on the release of the fibrinopeptides from fibrinogen is proposed. However, it cannot be guaranteed that "silent" residues in that reaction will necessarily be silent with respect other protein substrates. In such situations, decreased catalytic efficiency and/or binding affinity (loss of function) and/or increased efficiency (gain of function) could occur and be different depending on the substrate. Rather than being a limitation, the availability of a suitable reference material and measurement procedure can be expected to aid in identifying interactions that otherwise would be missed or discounted because of inadequate reference materials against which to unambiguously make comparison of the new effects. Anticipating what will be discussed later, fibrinogen is the substrate for which interactions with thrombin's active and extended active site and exosites are best described and understood.

\subsection{Biological Process in Which Thrombin Is Produced}

To permit understanding of the two most common and most problematic structural heterogeneities in thrombin preparations, it is useful to briefly review the process(es) by which thrombin is formed. Thrombin is formed from its circulating precursor, prothrombin, as the consequence of two necessary proteolytic cleavages. Depending upon the protease, or enzyme complex, employed in the conversion of prothrombin to thrombin, intermediates can be formed, with potentially complicating consequences. The relevant product for action on fibrinogen is $\alpha$-thrombin.

The pathways by which thrombin is formed from human prothrombin are shown in Fig. 9 [77]. Although the final product is $\alpha$-thrombin, an intermediate form of thrombin, meizothrombin, is also formed. As the result of factor Xa catalyzed catalysis, meizothrombin is transformed into $\alpha$-thrombin. Only $\alpha$-thrombin is an efficient protease for converting fibrinogen into fibrin; meizothrombin is only $1 \%$ as effective as $\alpha$-thrombin [60]. Some snake venom enzymes are also used for preparing thrombin from prothrombin [61, 62]; these produce principally meizothrombin, which then converts to $\alpha$-thrombin. For producing recombinant thrombin, 
the thrombin precursor prethrombin 2 is prepared and converted to thrombin by the enzyme from Echis carinatus [9-11]. The snake venom enzymes are particularly convenient and more readily available then the complex components of the physiological prothrombin activator (prothrombinase ${ }^{2}$ ) and are thus practical and widely used "tools" for converting prothrombin to thrombin [63, 64], particularly in identifying functional defects in patients with coagulation deficiencies.

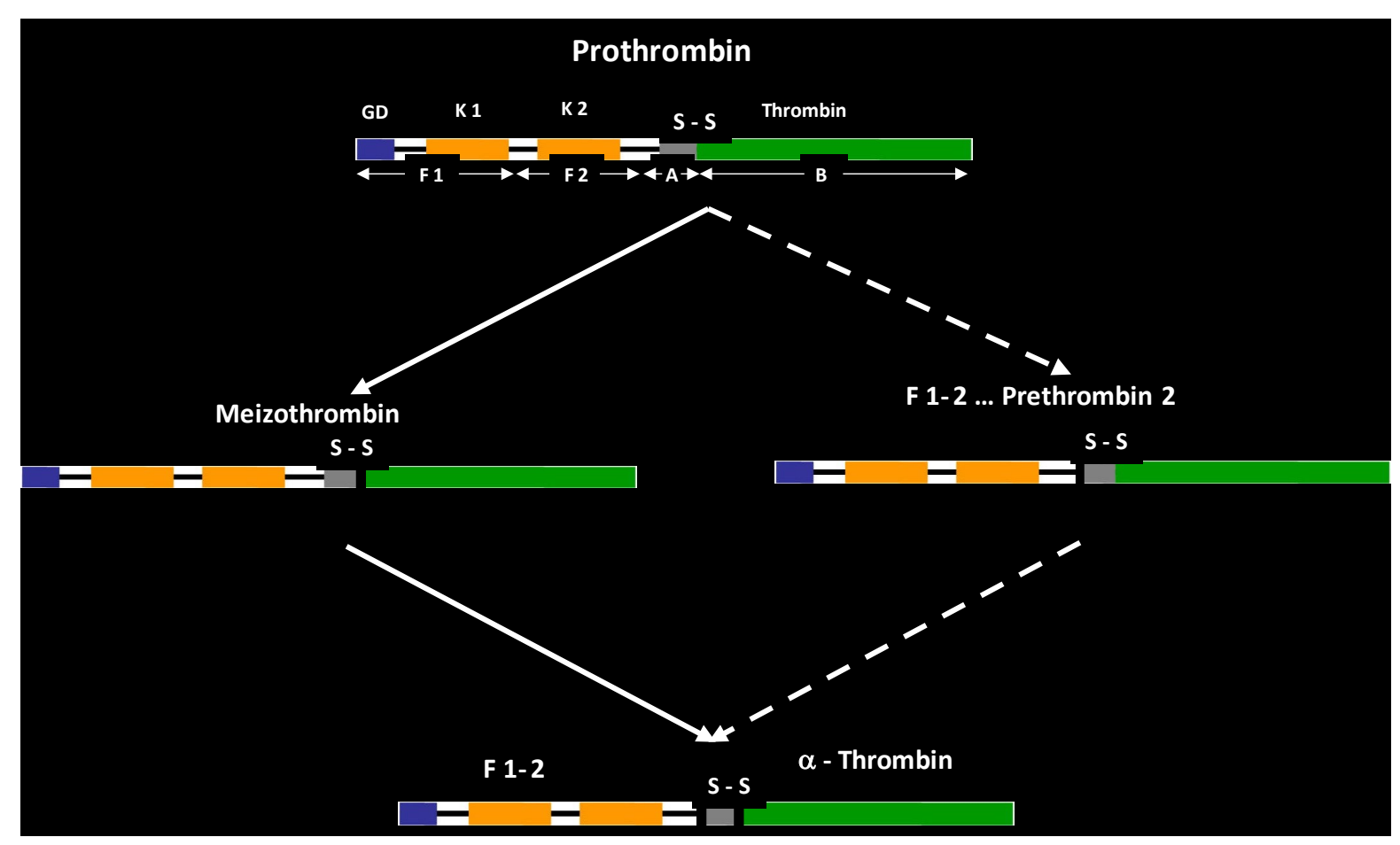

Fig. 9. The parallel pathways by which thrombin is produced from prothrombin. The form of thrombin that is active on the multiplicity of its protein substrates is $\alpha$-thrombin, the final product of this pathway. Depending on the activator (prothrombinase or the snake venom protease used), the intermediate form meizothrombin is formed very transiently (prothrombinase; factor Xa is the active protease), or it can be a primary product (proteases from Echis carinatus venom or Oxyuranus scutellatus venom). In addition, $\alpha$-thrombin can be further cleaved to form $\beta$ - and $\gamma$-thrombins - forms that have lost the specificity of $\alpha$-thrombin and that, when present in $\alpha$-thrombin preparations, confound the interpretations of thrombin action and severely limit the quality and thus utility of reference materials for thrombin (see Table 1). Figure was modified from Ref. [77].

The most important feature for producing a suitable reference material for $\alpha$-thrombin is the absence of the proteolytic degradation products: $\beta$-thrombin and $\gamma$-thrombin. These proteolytically degraded thrombins are less than $0.05 \%$ as effective as $\alpha$-thrombin $[65,66]$ in cleaving the fibrinopeptides from fibrinogen and inactivation by antithrombin [108]. Structurally, these two degraded forms of thrombin differ in molecular weight from $\alpha$-thrombin by only one or two molecules of water, respectively (Fig. 10). Preventing the formation of these degraded forms of thrombin and/or eliminating them from preparations of $\alpha$-thrombin are the most important steps in preparing a suitable reference material for thrombin.

\footnotetext{
${ }^{2}$ Prothrombinase is the name given to the mixture of factor Xa, factor Va, phospholipid vesicles, and $\mathrm{Ca}^{2+}$. It is used rarely because few laboratories produce the protein components required for this activator. Proteolysis of prothrombin to form thrombin and the activation fragments can be achieved by factor Xa alone, albeit at such a slow rate that high concentrations of factor Xa are required [77, 104, 1].
} 

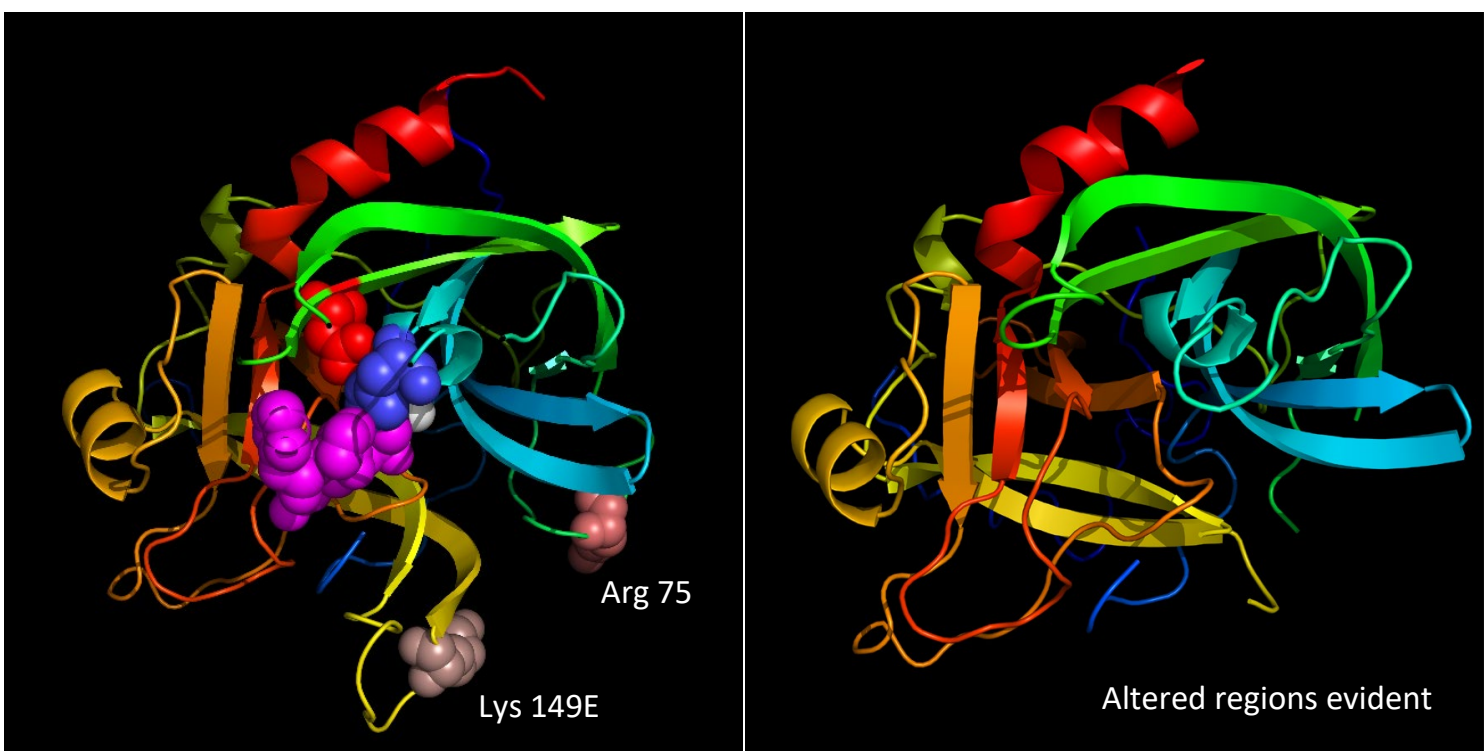

Fig. 10. Cleavage sites that convert $\alpha$-thrombin to $\beta$-thrombin and $\gamma$-thrombin. Cleavage of $\alpha$-thrombin at $\operatorname{Arg}$ (75, chymotrypsin numbering) produces $\beta$-thrombin. Cleavage of $\beta$-thrombin at Lys (149E, chymotrypsin numbering) produces $\gamma$-thrombin. Data are from Ref. [109]; thrombin structure is 1PPB from Refs. [22, 67].

\subsection{Critical Functional Consequences of Structural Changes in $\beta$ - and $\gamma$-Thrombins}

Thrombin's peptide bond specificity, like that of trypsin, is for the amide bond of basic amino acid residues, primarily arginine and secondarily lysine. All forms of thrombin (meizothrombin, $\alpha$-thrombin, $\beta$-thrombin, and $\gamma$-thrombin) hydrolyze arginyl and lysyl peptide bonds in low-molecular-weight synthetic substrates. Because of their convenience, these substrates are attractive for use in assessing thrombin proteolytic activity. However, they do not adequately distinguish between $\alpha$ - and $\beta$ - or $\gamma$-thrombins $[68,69$, $106,107]$, thus making them of no use for a reference measurement procedure. This is in marked contrast to the different forms of thrombin efficiency in proteolysis of protein substrates. Examples of the large magnitude of the kinetic differences are given in Table 1. However, there are routine methods that involve measurement of generated thrombin using peptide chromogenic or fluorogenic substrates for which they are completely appropriate; these routine methods are not discussed here.

\subsection{Thrombin "On Paper" Versus Thrombin the Isolated Substance}

Some historical context again may be useful for appreciating the technical challenges and requirements for a thrombin reference material if it is to be deemed suitable for its intended use as a highest-order reference material for both substance amount and biological activity. ${ }^{3}$ Isolation of thrombin from blood plasma can be achieved by a variety of procedures. Initially, the most homogeneous preparations have begun with a fraction of mixed plasma proteins, Cohn fraction II + III from ethanol precipitation [70, 71], or a similar fraction prepared by diethyl either precipitation [72]. These were by-products of therapeutic plasma fraction production.

\footnotetext{
${ }^{3}$ This point is reiterated because thrombin preparations of ambiguous or dubious suitability are still employed as reference materials in some methods used in pharmaceutical product evaluation.
} 
Table 1. Comparison of action of $\alpha$-thrombin and $(\beta, \gamma)$-thrombins on substrates and reaction with inhibitors.

\begin{tabular}{|c|c|c|c|c|c|}
\hline \multirow[b]{2}{*}{ Substrate } & \multicolumn{2}{|c|}{$\begin{array}{c}\text { Catalytic Efficiency, } \\
\mathrm{k}_{\mathrm{c}} / \mathrm{K}_{\mathrm{m}}\left(\mathrm{L} / \mathrm{mol} \mathrm{s}^{-1}\right)^{4}\end{array}$} & \multirow[b]{2}{*}{$\alpha /(\beta, \gamma)$} & \multirow[b]{2}{*}{ Note } & \multirow[b]{2}{*}{ Ref. } \\
\hline & $\alpha$-Thrombin & $\beta$-, $\gamma$-Thrombin & & & \\
\hline Tosyl-Gly-Pro-Arg-pNA & $2.6 \times 10^{7}$ & $1.1 \times 10^{7}$ & 2.4 & & [106] \\
\hline D-Phe-Pip-Arg-pNA & $5.5 \times 10^{7}$ & $4.2 \times 10^{7}$ & 1.3 & $\gamma$-thrombin & [105] \\
\hline Fibrinogen & $1.17 \times 10^{7}$ & $5 \times 10^{3}$ & 2400 & $\begin{array}{l}\text { Fibrinopeptide A (FpA) } \\
\text { release }\end{array}$ & [107] \\
\hline Fibrinogen & & & $>80$ & & [105] \\
\hline Factor XIII & $1.5 \times 10^{5}$ & $2.6 \times 10^{4}$ & 5.8 & Peptide release & [107] \\
\hline Antithrombin & $1.1 \times 10^{4}$ & $3.7 \times 10^{3}$ & 3 & Thrombin activity loss & [108] \\
\hline Antithrombin & $1.1 \times 10^{4}$ & $7 \times 10^{3}$ & 1.6 & Thrombin activity loss & {$[73]$} \\
\hline Antithrombin & & & $\approx 1$ & Probe displacement & [107] \\
\hline Protein $\mathrm{C}$ & & & $\approx 40$ & $\begin{array}{l}\text { In the presence of co factor } \\
\text { thrombomodulin }\end{array}$ & [113] \\
\hline \multicolumn{6}{|l|}{ Inhibitor (Exosite 1) } \\
\hline Hirudin ( $\beta$-thrombin) & $1.1 \times 10^{9}$ & $1.7 \times 10^{7}$ & 6.5 & Rapid kinetics & {$[74]$} \\
\hline Hirudin ( $\gamma$-thrombin) & $1.1 \times 10^{9}$ & $1.3 \times 10^{4}$ & 85,000 & & {$[75]$} \\
\hline
\end{tabular}

For biochemical research, precipitates were produced by adding $\mathrm{BaCl}_{2}$ to $\mathrm{Na}$ citrate anticoagulated plasma or $\mathrm{BaSO}_{4}$ to $\mathrm{Na}$ oxalate anticoagulated plasma $[76,77]$. Such preparations were frequently called "prothrombin" because thrombin would be produced from them [78]. However, these initial products were mixtures of all the vitamin K-related coagulation factors: prothrombin, factors VII, IX, and X, and subsequently identified proteins given the names protein $\mathrm{C}$, protein $\mathrm{S}$, and protein $\mathrm{Z}[79,80]$. The term "prothrombin complex" has been used to describe these preparations [81, 82]. After "activation," the capability to cause clotting led to the product being called thrombin, but confusion often resulted from variable results of the use of such "thrombin" forms. After the introduction of ion-exchange cellulose for protein purification, other clotting factors were isolated from the commercial "thrombin" [3, 4]. In consequence, early literature is confusing, and the conclusions drawn from many experiments reported as late as the 1970s are no longer meaningful $[83,124]$.

Purification to relatively high degrees of homogeneity became possible with the introduction of dextranbased ion exchange, gel filtration media, and the analytical electrophoresis methods such as "disc gel" electrophoresis [84] in the both the absence [137] and presence of sodium dodecyl sulfate [85] in the 1960s and 1970s. The first large-scale purification of vitamin K-dependent coagulation factors that focused on purity (homogeneity) by these procedures were done by two authors of this document $[86,121]$. Ignorance of the previously noted insight "....purity is a concept that has no meaning except with reference to the methods and assumptions used in studying the substance..." [12] regrettably resulted in much of the work done on thrombin being of indeterminable validity, and thus that work is now lost in oblivion.

Purification methods, beginning with a Cohn fraction [116] and now chromatography, can produce thrombin of consistent high quality as assessed both by both homogeneity and biological activity (specific activity, i.e., activity units/mass) criteria when calibrated against an international "standard" $[6,87,88]$. However, the analytical data attesting to the quality of the preparations, particularly as they relate to substance amount, are commonly not available, and thus material certified to metrological standards is still not available. Some of the available materials may be entirely suitable, but regrettably the evidence that they are suitable is not available, thus precluding their use in a metrologically rigorous calibration process.

\footnotetext{
${ }^{4}$ For hirudin, the constant is the on-rate constant. Reaction conditions and compositions are omitted because the two forms of thrombin were measured under the same conditions.
} 
As noted above, methods for preparing thrombin (human) that is homogeneous by the criteria of exclusion of known other proteins have been employed in research laboratories since the 1970s, all following similar purification strategies. Initial preparation of prothrombin that is freed from the other vitamin $\mathrm{K}$-dependent clotting proteins by anion- and cation-exchange chromatography is the common approach [89, 122]. Additionally, "affinity" chromatography using heparin or dextran sulfate linked to commercially available agarose beads has been used both for prothrombin and other vitamin $\mathrm{K}$-dependent clotting factor purification [90] and for thrombin purification after it has been produced by prothrombin activation [105]. Conversion of prothrombin to thrombin is achieved using snake venom proteases as well as the physiological activator prothrombinase. Of the snake venom activators used, those from Echis carinatus [100] or Oxyuranus scutellatus $[98,99]$ are most common. A key to avoiding the formation of $\beta$ - and $\gamma$-thrombins is rapid activation and purification to remove the activation fragments that arise from the amino terminal half of prothrombin. Degradation of $\alpha$-thrombin is believed to be autocatalytic [113], which occurs inefficiently by $\alpha$-thrombin but relatively rapidly by $\beta$ - or $\gamma$-thrombin once they are detected in the thrombin preparation. Separation of the activation fragments of prothrombin from thrombin is readily achieved by anion-exchange chromatography [122]. Separation of the activation fragments is important because they bind noncovalently to thrombin and alter the catalytic activity of $\alpha$-thrombin [79].

\subsection{Purity, Homogeneity, and Heterogeneity of Thrombin Preparations}

The combination of anion- and cation-exchange chromatography also offers evidence for the absence of contaminating proteins and prothrombin activation fragments. The two activation fragments are highly anionic and thus bind to the anion-exchange column stationary phase and require high salt concentrations for elution. Thrombin, being cationic, does not bind to an anion exchanger and elutes in the excluded volume of the anionexchange column at low salt concentration. The prothrombin activation fragments elute in the excluded volume of the cation exchanger, whereas thrombin is eluted with a gradient of salt concentration. Additionally, measurement of biological activity across the peak of eluting protein permits exclusion of protein that does not exhibit constancy of the ratio of activity to mass, with mass concentration commonly estimated by ultraviolet (UV) absorption spectrophotometry. Constancy of this ratio provides another type of evidence for homogeneity of the thrombin.

Reversible, low-molecular-weight inhibitors of thrombin have been used to minimize proteolytic degradation of thrombin during chromatography; however, the most common inhibitor, benzamidine $\mathrm{HCl}$, absorbs UV strongly and thus reduces the precision of protein concentration measurement by UV absorption. Selection of the $\mathrm{pH}$ at which thrombin is minimally active for elution also reduces proteolytic degradation. These considerations are noted because it was observed that prothrombin is more susceptible to proteolysis by thrombin during chromatography. Presumably, this is due to conformational alterations associated with binding to the ion-exchange material that result in increased cleavable peptide bond exposure. Based on the combined anion/cation chromatographic separation approach, which in principle "pulls away" contaminants of opposite charge properties, unwanted substances are "pulled away" from the thrombin. This is because during chromatography, the desired protein, if it elutes later from the column than the contaminants, can displace traces of the earlier-eluting unwanted proteins, thus contaminating the desired protein.

Analytical approaches unrelated to chromatographic elution behavior add further evidence for purity, i.e., absence of heterogeneity as related to contamination of other known substances. Electrophoretic separation methods provide evidence for the absence of contaminants, although overloading with respect to $\alpha$-thrombin is required to achieve detectability of contaminants with these methods. Labeling thrombin at its active histidine site provides a method that increases the sensitivity for detection of $\alpha$-thrombin degradation because the proteolytic cleavages that produce $\beta$ - and $\gamma$-thrombins occur in the chain containing the active site (the active site containing the heavy chain is also called the B-chain). The $\beta$ - and $\gamma$-thrombins cannot be distinguished, but as the objective is to identify the presence and amount, not the identity, of these degraded forms, this is a powerful method. Derivatized peptide chloromethyl ketones that react with the thrombin active site histidine 
(Fig. 5) react rapidly with thrombins, are covalently attached, and can have fluorophores and/or radioactive tags attached to facilitate detection and quantification [91]. Thrombin labeled with one such peptide chloromethyl ketone, D-Phe-Pro-Arg- $\mathrm{CH}_{2} \mathrm{Cl}$, enabled the first crystallization of thrombin for threedimensional structure determination (Fig. 5). These active site-labeled thrombins are also suitable for peptide mapping by high-performance liquid chromatography (HPLC) with MS detection. Locations of known mutations are illustrated in the following figure. (Fig. 11). Unique peptides from thrombin after controlled proteolysis by trypsin are given in the UniProt database, under Feature View, Proteomics, and they are reproduced in Fig. 12.

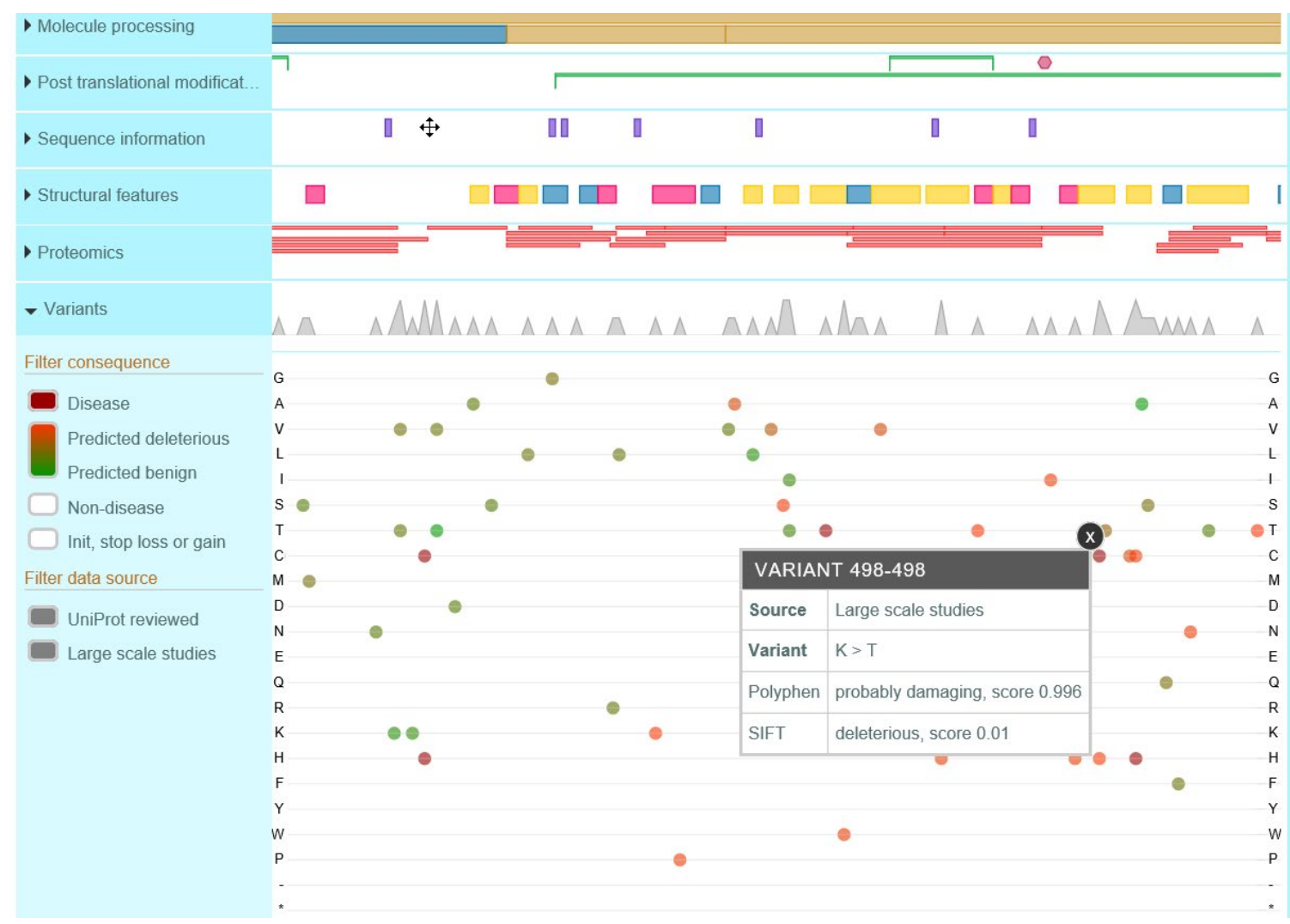

Fig. 11. UniProtKB - Documented amino acid variants in thrombin, showing one option in the Feature View display in UniProtKB that identifies variants and suggests a functional consequence of the amino acid substitution. 


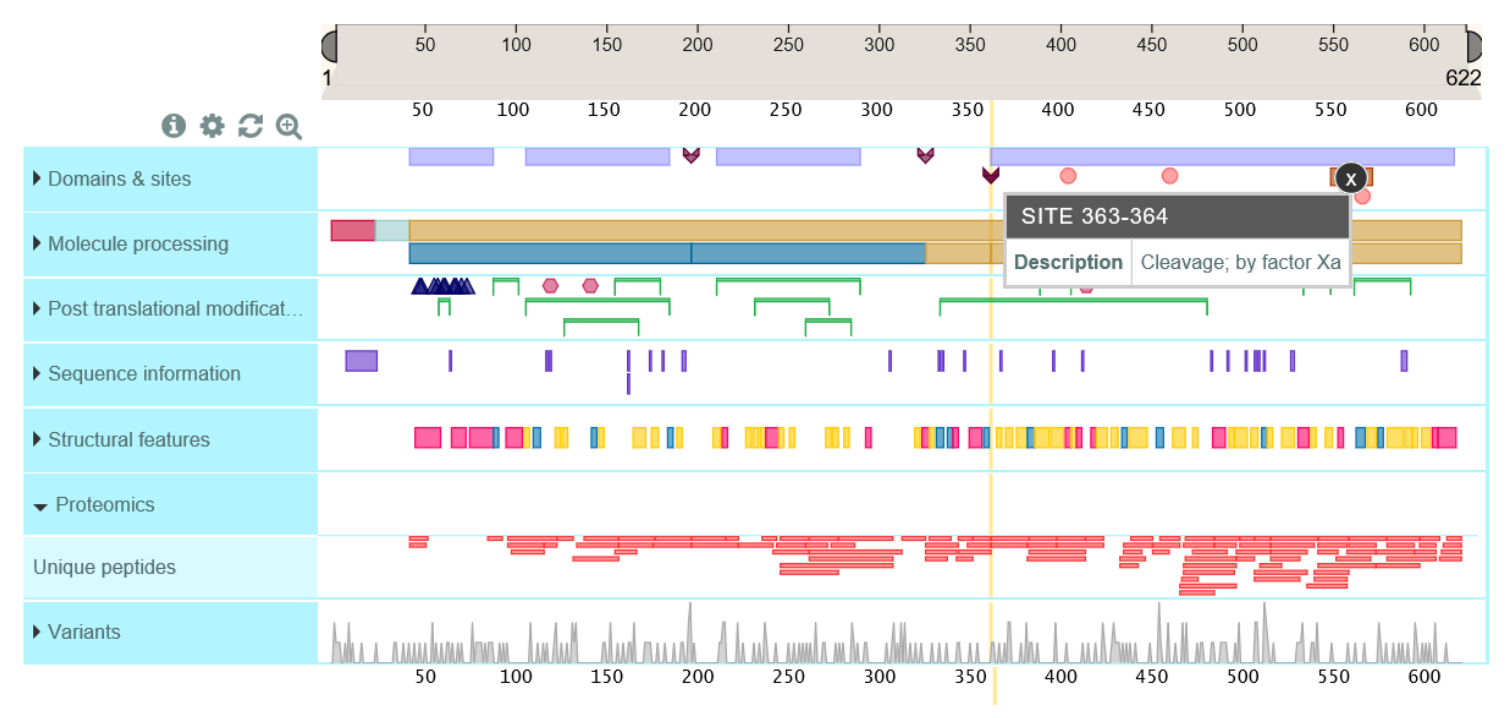

Fig. 12. UniProtKB - Diagrammatic presentation of unique peptide after proteolytic digestion. Utility is for predicting MS peptide data that, when combined with the variant data (Fig. 11), can permit targeted examination of a proposed reference material and the possibility of identifying functional consequences from variants present in the material.

\subsection{Structural Heterogeneity—Polymorphisms and Mutations}

Polymorphisms of genetic origin exist that may confound interpretation of the biological function measurements if present in a highest-order reference material. Many have been identified and are noted in the UniProt database, under Feature View, Variants. Mutations identified from functional impairment in individuals with mutations are given, as well as sequence conflicts reported by different laboratories. Based on structural information and inferences, predictions of sequence variant effects on function are given in this section (see also Fig. 11). Most of the variants are predicted to be of minor importance for function; however, only actual data that are traceable to a suitable reference material and method are needed to establish significance or insignificance. Experimental verification would require activity measurement on thrombin isolated from plasma of the individual with the variant or a recombinant product created to possess the variant residue. Such studies are beyond the purview of the development of a traceable reference material for thrombin.

An additional source of heterogeneity in thrombin is in the oligosaccharide chain attached to Asn in the thrombin heavy chain (see Figs. 5 and 13). Structurally, the oligosaccharide chain is similar in both human and bovine thrombins; fucosyl residues in the human chain are the major difference [92, 93]. No difference was observed in clotting activity after desialylation and other monosaccharide residue removal, indicating no significance of the oligosaccharide chain in function by this criterion [94, 95]. Charge heterogeneity was observed by isoelectric focusing because of sialic acid residue differences among thrombin molecules [96]; however, no effect on thrombin's ability to cause clotting was observed. Currently, nothing is known about the consequences of oligosaccharide chain heterogeneity on the immunoassay of thrombin, although immunoassay for thrombin has been employed in research investigations [97]. 

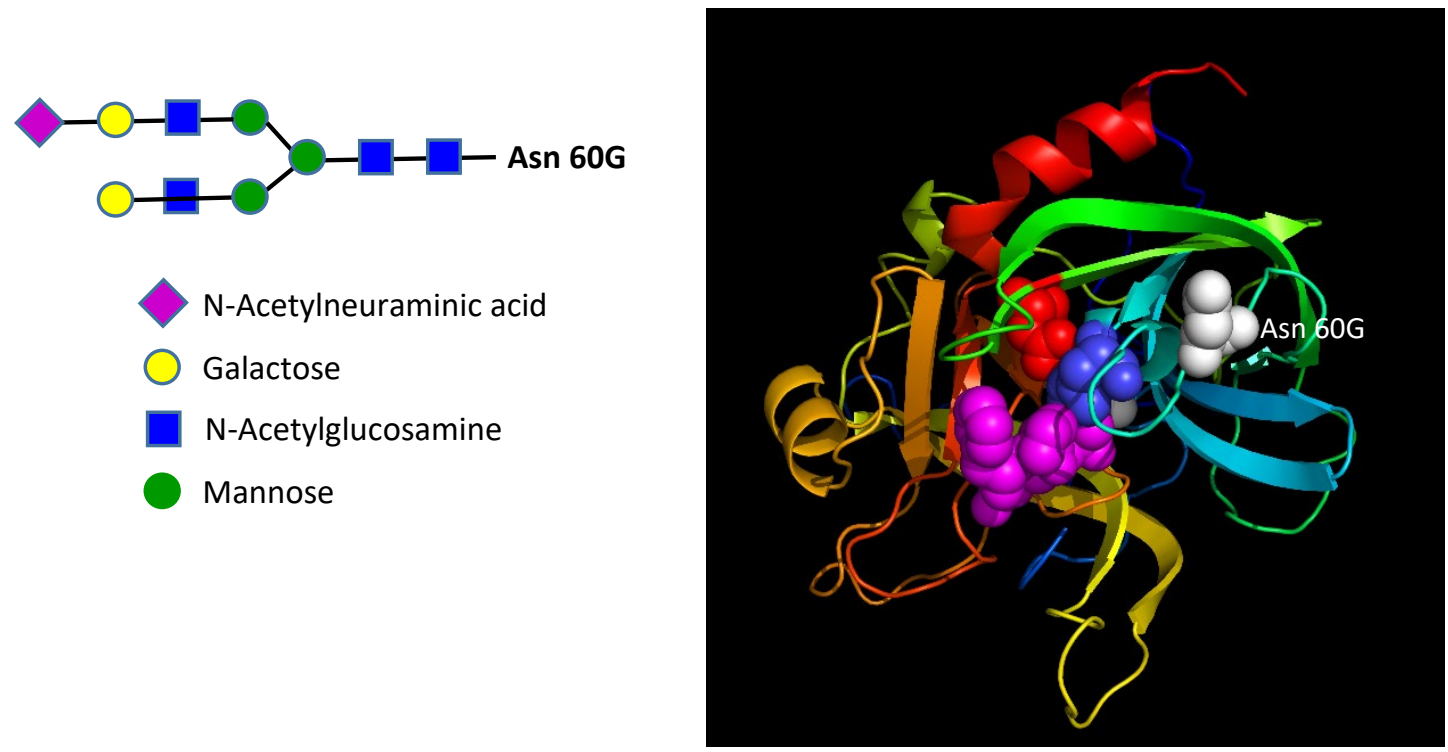

Fig. 13. The structure of the oligosaccharide chain at Asn $60 \mathrm{G}$ in thrombin, which is the single oligosaccharide chain present in thrombin. No functional consequence has been identified in relation to the oligosaccharide chain. Nomenclature is Asn 60G (chymotrypsin numbering) or Asn 416 (prothrombin numbering). Figure is derived from UniCarbKB, P00734.

\subsection{Physical Characteristics of Human Thrombin}

A summary of the considerations addressed above in identifying the substance, and the relevant physical properties useful in the preparation and characterization of the reference material are given in Table 2. Primary structure determinations (amino acid sequence), particularly as reflected in the UniProt database, and threedimensional structures determined by crystallographers with historical ties to earlier protease crystal structures have resulted in several numbering systems in publications related to thrombin. These alternative numbering systems are detailed in the Appendix.

Table 2. Kinetic parameters for $\alpha$-thrombin action on fibrinogen.

\begin{tabular}{|c|c|c|c|c|}
\hline $\begin{array}{c}\text { Specificity Constant, } \mathrm{k}_{\mathrm{c}} / \mathrm{K}_{\mathrm{m}} \\
\left(\mathrm{L} / \mathrm{mol} \mathrm{s}^{-1}\right)\end{array}$ & $\begin{array}{c}\text { Michaelis Constant, } \\
\mathrm{K}_{\mathrm{m}}{ }^{\mathrm{c}}(\mathrm{L} / \mathrm{mol})\end{array}$ & $\begin{array}{c}\text { Kinetic Constant, } \mathrm{k}_{\mathrm{c}} \\
\left(\mathrm{s}^{-1}\right)\end{array}$ & $\begin{array}{c}\text { Reaction Conditions: } \\
\mathrm{pH}, \mathrm{NaCl}(\mathrm{mol} / \mathrm{L}), \mathrm{Temp}\left({ }^{\circ} \mathrm{C}\right), \text { species }\end{array}$ & Ref. \\
\hline $1.09 \times 10^{7} \mathrm{FpA}$ & $(7.2 \pm 0.9) \times 10^{-6}$ & $84 \pm 04$ & $7.4,0.137,37$, human & {$[98,99]$} \\
\hline $6.5 \times 10^{5} \mathrm{FpB}(\mathrm{GPRP})^{\mathrm{a}}$ & $(7.2 \pm 1.5) \times 10^{-6}$ & $48 \pm 5$ & $7.4,0.137,37$, human & {$[100]$} \\
\hline $4.2 \times 10^{6} \mathrm{FpB}\left(\mathrm{F}_{\mathrm{m}}\right)^{\mathrm{b}}$ & - & - & $7.4,0.137,37$, human & {$[154]$} \\
\hline $\begin{array}{c}\text { Indeterminant, based on } \\
\text { clotting time }\end{array}$ & $(13.3 \pm 1.1) \times 10^{-6}$ & Not measurable & $7.5,0.25,37$, human & {$[101]$} \\
\hline $\mathrm{FpA}$ & $(11 \pm 3) \times 10^{-6}$ & $79^{\mathrm{d}}$ & $7.26,0.3,25$, bovine & {$[102]$} \\
\hline $\mathrm{FpB}$ & $(6.0 \pm 8.5) \times 10^{-6}$ & $44^{\mathrm{d}}$ & $7.26,0.3,25$, bovine & {$[156]$} \\
\hline
\end{tabular}

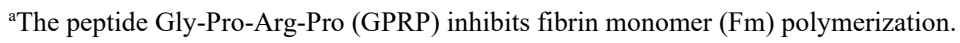

${ }^{b}$ Increase in the rate of $\mathrm{FpB}$ cleavage by polymerization of fibrin monomers; $\mathrm{k}_{\mathrm{c}} / \mathrm{K}_{\mathrm{m}}$ increased for FpB release by 6.5 times.

${ }^{c}$ Values for $K_{m}$ are measured by competition with the chromogenic substrate D-Phe-Pip-Arg-pNA; $k_{c}$ values are not determinable by this method.

${ }^{\mathrm{d}}$ Estimated using $7.9 \times 10^{-12} \mathrm{~mol} / \mathrm{L}$ for the concentration of thrombin given as $1 \mathrm{unit} / \mathrm{L}$. 


\section{Summary}

The availability of well-documented methods for purification of the thrombin precursor, prothrombin, and the conversion of prothrombin to thrombin suggests that preparation of the primary, highest-order thrombin reference material and secondary reference materials of essentially equal quality is not only feasible but straightforward enough for widespread use.

Characterization of the reference material is crucial for its utility and widespread acceptance. MS detection after tryptic digestion and peptide separation by HPLC, as an example, will serve to establish definitive data for the certificate of analysis for the reference thrombin. Through isotope- or chromophore/fluorophore-labeled samples, the presence and amount of the two degraded forms of thrombin can be quantified, thus enabling compensation for any interference caused by the presence of these species that may confound a substrate-dependent thrombin activity assay.

\subsection{Reference Material for Identity}

Despite the complexity and the inherent heterogeneities, a metrologically traceable reference material for thrombin is both feasible and can be suitable for its intended use. The extensive data set for thrombin that is the result of decades of structure-function studies provides a satisfactory basis upon which to select an amino acid sequence that identifies and thus defines thrombin as a protein substance. Characterization of the sequence heterogeneities, now entirely practical by MS, enables new observations of structural differences that have functional consequences. This can be done without adversely affecting the utility of the reference material and can enhance the utility of the certificate of analysis for the reference material.

A consensus sequence that broadly reflects the most prevalent amino acid sequence throughout the world is the most desirable. The identification of the differences among populations can assure appropriate compensation for the differences, if required. Through use of the available information on mutations, both naturally occurring and site-directed variants of thrombin can be excluded, if function data indicate that the mutation will cause bias in measurements of thrombin biological activity(ies). Errors in judgment with respect to either loss or gain of function for thrombin action on any of its many substrates can be explicitly described, and, as for any situation of bias (systematic error), a correction can be made for this bias.

\subsection{Reference Measurement Procedure for Thrombin Proteolytic Activity}

Although increasingly observed for many biological macromolecules, the multiplicity of substrates for enzymes creates a challenge in the design of a reference measurement procedure. For thrombin, lowmolecular-weight peptides with convenient chromophores for monitoring thrombin-catalyzed hydrolysis as a measure of thrombin activity are appealing. However, substance amount cannot be determined in this manner. Physiologically, thrombin's target substrates are large protein substrates, e.g., 20 times the mass of thrombin with multiple peptide bonds being cleaved. A key to achieving a high degree of comparability of the measurement results and the inferences made from them is the reference material. The chemical properties described for the thrombin reference material enable inference from activity measurement to substance amount, which must underpin the proposed reference measurement procedure.

\subsection{Selection of the Most Appropriate Substrate for Measurement of Thrombin Biological Activity}

Selection of a single substrate, fibrinogen, that enables definition of the measurand most suitable for assessing thrombin proteolytic activity is most practically justified by eliminating first substrates that are less suitable. The principal criterion used in this proposal is: Proteolytic action on the substrate should reflect as completely as practical contributions of all structural features of the thrombin molecule known to influence the rate of proteolysis. Integrity of the following should all contribute to the activity measurement: 
(1) the active site (Fig. 2),

(2) the extended active site (Fig. 8),

(3) the exosites (Fig. 6),

(4) the sodium ion binding site (Fig. 7), and

(5) the presence of the degraded forms of thrombin.

Fibrinogen meets the specified criteria; the reasons why other substrates are unsuitable are detailed below.

Peptide chromogenic or fluorogenic substrates, although they are the most convenient and there exists the largest body of data for thrombin action on them, are disqualified because they measure only the integrity of the active site. They are further disqualified because of their inability to adequately distinguish between $\alpha$-thrombin and the degraded $\beta$ - and $\gamma$-thrombins. Although usable when the thrombin preparation is the proposed reference material, or when thrombin is indistinguishable from it as indicated by the characterization described for the reference material, the potential for bias and its detection make these substrates unsuitable for a reference measurement procedure.

Of the many protein substrates and receptors upon which thrombin proteolytic action or binding is established to be physiologically relevant, most are substances in low concentration in blood plasma or are located on cell surfaces. Proteins other than fibrinogen are impractical to isolate in the quantities required and are thus unsuitable. Consequently, factor XIII, factor XI, factor V, and factor VIII are eliminated from consideration. Protein $\mathrm{C}$ is not excluded; although not a high-concentration plasma protein, it is a by-product of prothrombin isolation and thus could be available. However, its physiologically relevant activation requires the participation of thrombomodulin, a membrane protein only present in small amounts and not readily isolatable in large quantity. Recombinant thrombomodulin could be considered, as could other recombinant proteins. For example, factor VIII could be considered, because it is commercially produced for treatment of hemophilia A. Contemporary preparations of factor VIII, however, are not structurally the same as natural factor VIII because of their greater efficacy, safety, and reduced immunogenicity. Moreover, measurement of the action of thrombin on these other proteins is more complex than for fibrinogen.

\subsection{Selecting the Reaction That Defines the Measurand}

The criteria for selection of the substrate for a reference measurement procedure are best met by fibrinogen. The proteolytic cleavage of fibrinopeptides A and B produces two low-molecular-weight products that are readily separated from the other product, fibrin monomer, and several HPLC methods for quantifying the fibrinopeptides have been reported [154, 103, 104]. Because the peptides are 16 (fibrinopeptide A) and 14 (fibrinopeptide B) amino acid residues in length, internal standards for HPLC and MS can be prepared by chemical synthesis for use and validation of the HPLC methods. Figure 14 displays the crystallographicdetermined structure of fibrinogen. Figure 15 details the reaction of thrombin on fibrinogen, revealing the small changes that enable polymerization of fibrin monomer. 

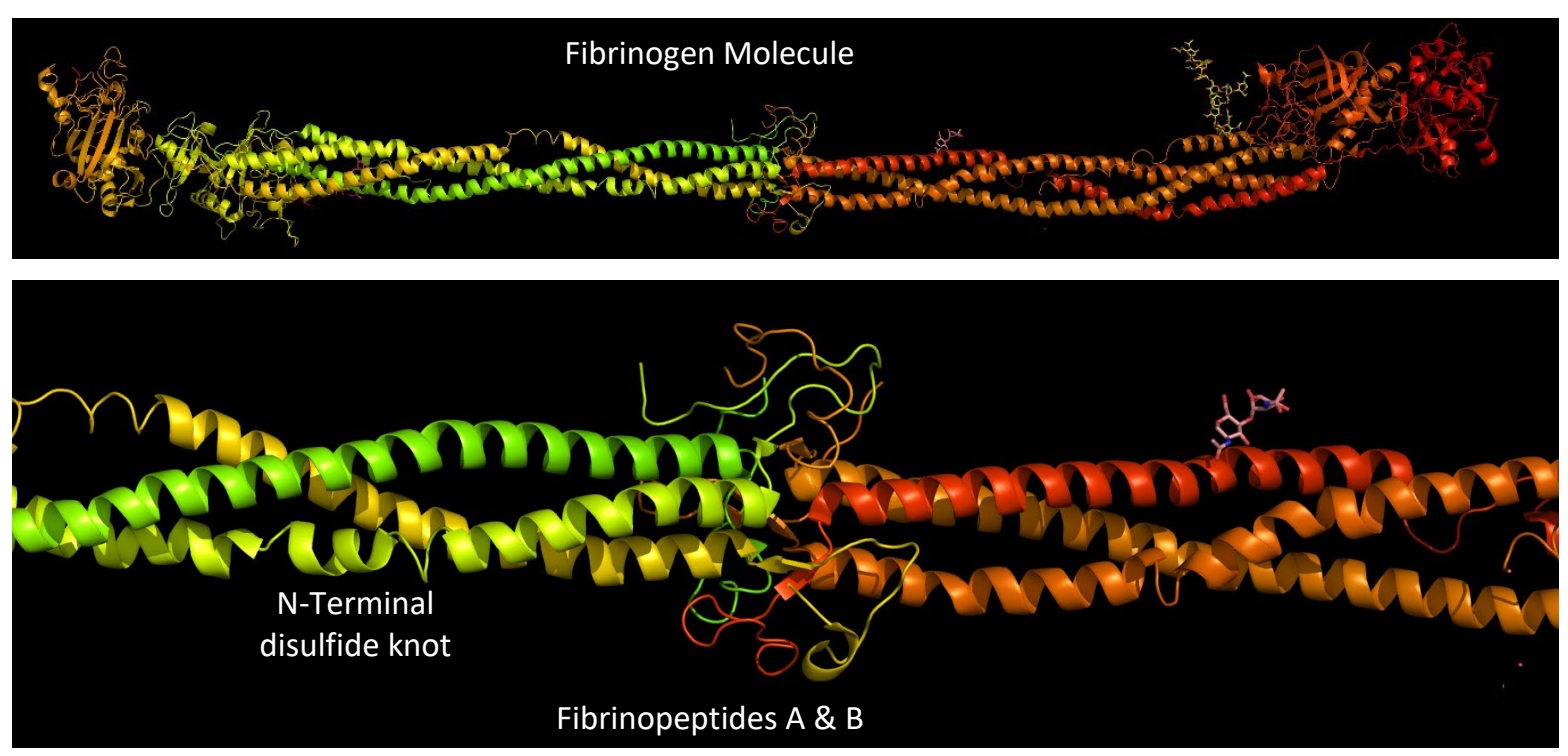

Fig. 14. Structure of fibrinogen and fibrinopeptides A and B. Fibrinopeptides A and B comprise a small part of the fibrinogen molecule, i.e., less than $2 \%$ of the total polypeptide sequence. Removal of the peptides exposes the polymerization site that interacts with the "knobs" at the ends of the structure to form fibrils. Derived from Refs. [105, 106].

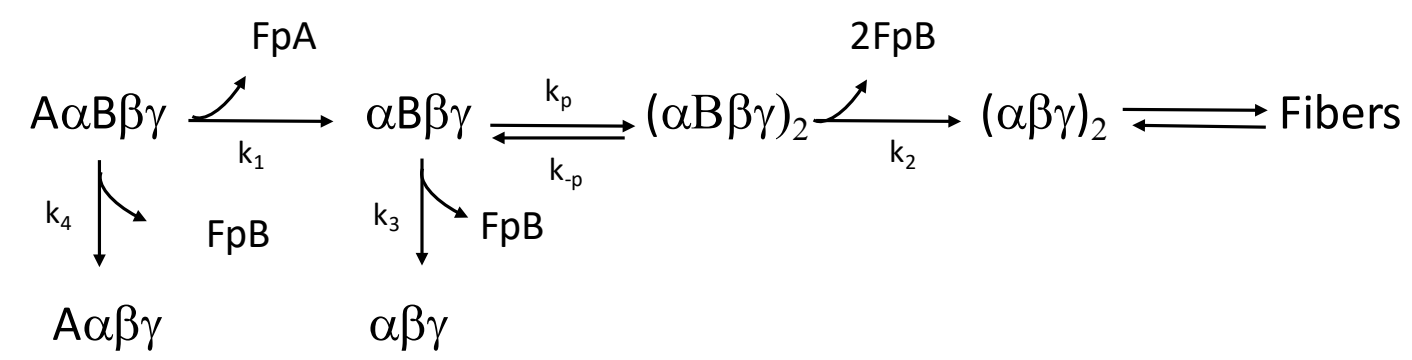

Fig. 15. Reaction pathway for release of fibrinopeptides. Fibrinopeptide A (16 residues) is cleaved prior to fibrinopeptide B (14 residues), implying that exposure of fibrinopeptide B must precede its cleavage from the B-chain of fibrin monomer, the product of fibrinopeptide A release. Derived from Ref. [107].

\subsection{Established Kinetic Behavior of the Thrombin-Catalyzed Release of Fibrinopeptides}

Consistent behavior for thrombin-catalyzed fibrinopeptide release has been reported over several decades, although the instrumentation and identification methods have been greatly refined over that period. The procedure outlined below is taken from Ref. [108] with only minor adaptations.

Values of the Michaelis constant and the maximum rate of reaction for both human and bovine proteins are listed in Table 2. Concentrations of thrombin and fibrinogen for the measurement are selected to simplify the kinetics of the reaction and thus make analysis of the concentration of the fibrinopeptide(s) versus time simple $[153,165]$. Further, when the concentration of the substrate is $<0.2 \mathrm{~K}_{\mathrm{m}}$ for thrombin, and the concentration of thrombin is much less than the fibrinogen concentration, the kinetic behavior is pseudo-first order. Although the action of thrombin on fibrinogen and the process of its transformation from soluble, circulating protein to the gelatinous clot have been long studied, the technological developments and elucidation of the kinetic mechanism in the 1970s through 1990s enabled this straightforward, rigorous procedure to be produced (Fig. 15). 
Reaction composition, reactant concentrations, and solution composition employed are summarized in Table 3. The identification of the $\mathrm{Na}^{+}$binding site on thrombin $[87,155,109]$ suggests that the $\mathrm{NaCl}$ concentration should be increased to $0.2 \mathrm{~mol} / \mathrm{L}$ to ensure that thrombin is in the "fast form." Inclusion of the tetrapeptide Gly-Pro-Arg-Pro [110,111] inhibits polymerization and reduces any complicating effects of fibrin polymerization. However, release of fibrinopeptide B is affected $[152,153,112]$, although, if fibrinopeptide A is exclusively measured, this will be of no significance.

Table 3. Reactant and reagent compositions for $\alpha$-thrombin action on fibrinogen.

\begin{tabular}{|c|c|c|c|}
\hline $\begin{array}{c}\text { Reactant } \\
\text { or Component }\end{array}$ & $\begin{array}{l}\text { Concentration (in } \\
\text { Reaction) }\end{array}$ & Notes & Ref. \\
\hline Fibrinogen & $2 \mu \mathrm{mol} / \mathrm{L}$ & $<0.2 \times \mathrm{K}_{\mathrm{m}}$, reaction is dependent on [fibrinogen] & [164] \\
\hline$\alpha$-thrombin & $1 \mathrm{nmol} / \mathrm{L}$ & [thrombin] $<<$ [fibrinogen], pseudo-first-order kinetic behavior & [163] \\
\hline $\mathrm{NaCl}$ & $0.2 \mathrm{~mol} / \mathrm{L}$ & {$\left[\mathrm{Na}^{+}\right]$to ensure all thrombin is in the "fast form" } & {$[83,165]$} \\
\hline Tris/HEPES & $0.05 \mathrm{~mol} / \mathrm{L}$ & Increasing buffer capacity for both acidic/alkaline shifts & [113] \\
\hline $\mathrm{H}^{+}$ & $\mathrm{pH} 7.8$ & $\begin{array}{l}\text { Slight plateau in } \mathrm{pH} \text { dependence curve; closer to plasma } \mathrm{pH} \text { than } \\
\text { maximum/plateau at } \mathrm{pH} \approx 8\end{array}$ & [114] \\
\hline PEG 8000 & $\begin{array}{c}0.1 \% \\
\text { (mass fraction) }\end{array}$ & $\begin{array}{l}\text { Competing adsorbate to prevent loss of thrombin by adsorption to } \\
\text { reaction vessel surface }\end{array}$ & $\begin{array}{c}{[169,170,} \\
115]\end{array}$ \\
\hline $\begin{array}{l}\text { Fibrinopeptide A } \\
\text { (deuterium label) }\end{array}$ & & Internal standard for HPLC quantification & [116] \\
\hline
\end{tabular}

Reactions are at $37.0^{\circ} \mathrm{C}$, the conventional temperature for enzyme assay. Reaction vessels are preferably polypropylene that has been coated with PEG 20,000 [170, 171]. Polypropylene microcentrifuge tubes $(1.8 \mathrm{~mL})$ are convenient for quenching and centrifugally removing precipitated fibrinogen and fibrin monomer. The first solution to be placed in the reaction vessel is fibrinogen to further minimize thrombin adsorption loss. The thrombin in solution is most stable at $\mathrm{pH} 6.5 \mathrm{in} 0.5 \mathrm{~mol} / \mathrm{L} \mathrm{NaCl}[116,117]$. The reaction is quenched with $3 \mathrm{~mol} / \mathrm{L}$ perchloric acid. The buffers listed above are Tris (2-amino-2-hydroxymethyl-propane-1,3-diol) and HEPES (4-(2-hydroxyethyl)-1-piperazineethanesulfonic acid).

Linearity with thrombin concentration, which is expected for simple enzyme-catalyzed reactions, is observed under the conditions of this method $[163,164]$. Linearity with fibrinogen concentration is achieved by the selection of the concentration to be $<0.2 \mathrm{~K}_{\mathrm{m}}$ [164]. The greatest advantage of this simplified kinetic behavior is that any laboratory with the HPLC equipment could perform the reference measurement procedure; reliance on special reference measurement service laboratories [117] would then not be required.

The release of both fibrinopeptides A and B under the conditions of the method as published here is described by the rate equations provided in Refs. [152, 53]. The kinetic equations for the full-time course of the reaction are also given in the published reports on which the procedure described above is based [152, 164]. Contemporary personal computer software now exists that can be used to fit the entire reaction time course, thus making it possible to eliminate the restrictions on reactant concentrations that are required for simple linear fibrinopeptide release with time. However, biasing because of contaminants in the fibrinogen preparations and other interactions can complicate the kinetic behavior observed in full reaction time course monitoring and thus influence the measurement results.

For metrological traceability to the International System of Units (SI), the activity of thrombin must be expressed in the appropriate SI unit, the katal [118]. This is readily done and thus provides metrological traceability to the SI; however, the katal has a unique value only under the specified conditions of the reference measurement procedure. 


\subsection{Fibrinogen Preparations-Suitability for the Reference Measurement Procedure}

Fibrinogen present in plasma, at concentrations between 200 and $400 \mathrm{mg} / \mathrm{dL}$ [119], is a practical choice because of its convenient availability and the large amounts that are available. Methods for purification of fibrinogen suitable for transfusion are varied; the simplest and best characterized date back to the 1960s. Commonly, fibrinogen "quality" is described by the percentage of the fibrinogen protein preparation that is capable of clotting; the clot is manually removed and weighed [120,121]. Although fibrinogen is commercially available from multiple sources, freedom of the material from factor XIII and plasminogen is important to avoid the complication of cross-linking (factor XIIIa) or proteolytic degradation by plasmin (plasminogen contamination). Other potential contaminants that could affect the quality of the fibrinogen substrate in the reference procedure are the thrombin-activated fibrinolysis inhibitor (TAFI), and tissue plasminogen activator. Changes due to the action of these enzymes on stored or suboptimally handled fibrinogen preparations can be minimized or avoided by suitably "pure" fibrinogen preparations.

In the time interval over which fibrinopeptide release is being measured, minor contaminants are unlikely to influence the behavior of the reaction. Fibrinogen preparations of different purity have been investigated and found to be suitable for use in measurement of fibrinopeptide release [154].

\subsection{Reaction Conditions, Influence Quantities, and Avoidance of Measurement Bias}

\subsubsection{Proton Binding- $\mathrm{pH}$}

As recognized for all enzymatic reactions, adequate buffering for kinetic measurements of fibrinopeptide release from fibrinogen is required. Optimum $\mathrm{pH}$, for both fibrinogen and peptide p-nitroanilide substrates, is at $\mathrm{pH} 8.0$; an inflection is observed at $\mathrm{pH} 7.8$ in $0.1 \mathrm{~mol} / \mathrm{L} \mathrm{NaCl}$ (ionic strength, $0.15 \mathrm{~mol} / \mathrm{L}$ ) [169, 122]. Based on the near identity of the $\mathrm{pH}$ dependence for both types of substrate, the effect appears to be predominately on thrombin. The results from several laboratories using different methods for monitoring the hydrolytic reaction illustrate the consistency of $\mathrm{pH}$ dependence $[163,169,123,124]$. Rationale for the selection of the most advantageous $\mathrm{pH}$ can be: (1) minimization of the effects on the measured reaction rate or (2) a pH at which buffer capacity minimizes changes in $\mathrm{pH}$. The latter was the criterion used in studies of the $\mathrm{pH}$ dependence of bovine thrombin on peptide p-nitroanilide substrates $[111,169,125]$. The value of $\mathrm{pH}$ is frequently selected to be that of plasma, $\mathrm{pH} 7.4[154,163,164,168]$. However, this is a region of $\mathrm{pH}$ dependence with a high slope, and thus it is potentially subject to $\mathrm{pH}$ variability that unnecessarily contributes to measurement uncertainty.

\subsubsection{Ionic Strength—Electrolyte Identity and Concentration Dependence}

It is necessary to select a $\mathrm{Na}^{+}$concentration that is appropriate for all thrombin being in the "fast form" (the optimal conformer for action on fibrinogen) but that minimizes thrombin action on thrombomodulinrelated activation of protein $\mathrm{C}$. Using peptide p-nitroanilide substrates acting on bovine thrombin, $\mathrm{K}_{\mathrm{m}}$ increases by 1.5 between $(0.1$ and 0.2$) \mathrm{mol} / \mathrm{L} \mathrm{NaCl}$ at $\mathrm{pH} 7.8 ; \mathrm{k}_{\mathrm{c}}$ is unchanged. Between $(0.2$ and 0.5$) \mathrm{mol} / \mathrm{L} \mathrm{NaCl}$, neither $\mathrm{K}_{\mathrm{m}}$ nor $\mathrm{k}_{\mathrm{c}}$ is changed [169]. Because of the specific ion effect of $\mathrm{Na}^{+}$(see below), $\mathrm{NaCl}$ concentration needs to be $>0.2 \mathrm{~mol} / \mathrm{L}[126]$ to ensure that all thrombin is in the optimal conformer for fibrinopeptide release. The residues implicated (Fig. 7) as well water molecules in the "site" are thus controlled, and any effects of them are minimized.

\subsection{3 $\mathrm{Na}^{+}$Effects on Thrombin Proteolytic Activity-Optimizing Specificity}

The two forms of thrombin that are modulated by $\mathrm{Na}^{+}$binding $[81,87]$ differ in their relative specificity on fibrinogen and other protein substrates (Fig. 7). Selecting the $\mathrm{NaCl}$ concentration to exceed $0.2 \mathrm{~mol} / \mathrm{L}$ forces the thrombin into the "fast form," the form best suited for measuring thrombin proteolytic activity on 
fibrinogen and synthetic substrates. Alteration of thrombin activity and stability by other ions has also been reported [82, 127, 128].

\subsubsection{Divalent Cations $-\mathrm{Ca}^{2+}$ Ions and Thrombin Action on Other Substrates}

Two effects of $\mathrm{Ca}^{2+}$ on the proteolysis of fibrinogen by thrombin require consideration. First, $\mathrm{Ca}^{2+}$ binding to fibrinogen affects fibrinopeptide B release; fibrinopeptide A release is minimally affected [129, 130, 131]. Fibrinogen is stabilized by $\mathrm{Ca}^{2+}[187,132,133]$, and so it might be important to have $\mathrm{Ca}^{2+}$ present for fibrinogen to be used over long periods of time. Second, activation of factor XIII is dependent on $\mathrm{Ca}^{2+}$, suggesting that the absence of $\mathrm{Ca}^{2+}$ can minimize any bias that might occur if the fibrinogen were contaminated with factor XIII. There is no effect of $\mathrm{Ca}^{2+}$ on thrombin kinetic parameters for peptide p-nitroanilide substrates when assessed with thrombin (bovine) [169]. In the proposed reference procedure, bias from the presence of $\mathrm{Ca}^{2+}$ is unlikely; however, differences in the results from routine methods in which thrombin is used (commonly for turbidimetric measurement of fibrinogen) should be expected between $\mathrm{Ca}^{2+}$ containing and $\mathrm{Ca}^{2+}$-free solutions.

\subsubsection{Protein Substrates Other than Fibrinogen-Alternative Substrates as Competitive Inhibitors}

Thrombin is a protease with a substantial number of biologically important substrates. The approach to a reference measurement procedure described here is unlikely to suffer bias because of the presence of small amounts of these protein substrates, first, because of efforts to remove even trace amounts from the reference material, and second, because of the selection of the conditions under which thrombin proteolysis of fibrinogen is measured. However, when assigning values for thrombin substance amount and catalytic activity to calibrators along the traceability chain, i.e., calibrators that will be used in routine methods, these other substrates may be important. Some of the more well-known alternative substrates [134] of thrombin are listed in Table 4.

Table 4. Limited list of competing substrates and protein inhibitors of thrombin.

\begin{tabular}{|c|l|c|}
\hline Substrate & \multicolumn{1}{|c|}{ Name/Function } & Ref. \\
\hline Fibrinogen & Precursor of clot & {$[135,136]$} \\
\hline Factor XIII & Plasma transglutaminase; cross-links fibrin in clot & {$[168]$} \\
\hline $\begin{array}{c}\text { Protease-activated } \\
\text { receptors (PARs) 1,3,4 }\end{array}$ & Protease-activated receptors, found on cells, e.g., platelets & {$[95,96]$} \\
\hline Factor V & $\begin{array}{l}\text { Component of prothrombinase; catalyzes factor Xa cleavage of peptide bonds in } \\
\text { prothrombin }\end{array}$ & {$[26,77,191]$} \\
\hline Factor VIII & $\begin{array}{l}\text { Component of factor X activation complex; catalyzes factor IXa cleavage of peptide } \\
\text { bonds in factor X }\end{array}$ & {$[26,191]$} \\
\hline Factor XI & Factor XIa activates factor IX; sulfated polysaccharides can catalyze the reaction & {$[92,137]$} \\
\hline TAFI & Thrombin-activated fibrinolysis inhibitor & {$[138]$} \\
\hline Antithrombin & $\begin{array}{l}\text { Serine protease inhibitor of thrombin, factors Xa, IXa, VIIa; inactivation reaction is } \\
\text { catalyzed by heparin with unique pentasaccharide sequence }\end{array}$ & {$[74]$} \\
\hline Heparin cofactor II & $\begin{array}{l}\text { Serine protease inhibitor of thrombin; catalyzed by sulfated polysaccharides; no } \\
\text { specific saccharide sequence required }\end{array}$ & {$[139]$} \\
\hline
\end{tabular}

As influence quantities, alternative substrates are potential sources for bias. The extent to which these substrates create bias in a measurement result must be investigated whenever suspected. Although commutability is most frequently discussed as a matrix-related feature, the alternative substrates noted here are present when the matrix is blood plasma. When the alternative substrates interfere to such an extent that they are readily detectable, correction for them can be made by treating their reactions as conventional, parallel enzymatic reactions or as competitive inhibitors. An example of this is thrombin inactivation by its inhibitors, 
antithrombin, $\alpha-1$ antitrypsin ( $\alpha-1$ proteinase inhibitor), and $\alpha-2$ macroglobulin. This situation is noted in the entries in Table 4 and the references cited there.

A recently published routine method addressing interferences has the potential to improve the accuracy and help establish the metrological traceability of clinical measurement results for thrombin activity in plasma [140].

\subsubsection{Thrombin Adsorption Loss and Adsorption Prevention}

Thrombin action on fibrinogen, synthetic substrates, and other protein substrates, whatever the "signal" for monitoring the reaction, occurs at concentrations of thrombin at nanomoles per liter or lower [107, 152, 164]. Under these conditions, thrombin is rapidly adsorbed, and, depending on the surface, it can be irreversibly adsorbed. Adsorbed thrombin becomes inactive, thus changing its concentration in the reaction. Buffer solutions have commonly included plasma albumin of variable purity as a competing adsorbate; although effective in reducing adsorption loss, albumin prepared by some methods can be contaminated with enzymes and metal ions. Therefore, human albumin of drug quality is preferred.

Polyethylene glycol has been shown to be a better competing adsorbate and may stabilize thrombin as well as prevent adsorption [170]. Whenever possible, polypropylene containers, precoated with highmolecular-weight polyethylene glycol [171], have been found to be the most suitable for reaction vessels and for preparing dilutions of thrombin at higher concentrations than employed in the reactions.

\section{Discussion-A Traceability Scheme for Thrombin with Both Metrological and Philosophical Uncertainty}

A metrologically ideal measurement system includes both a reference material and a reference measurement procedure [141]. Without both, traceability to substance identity and measurement of substance amount and structure-derived biological activity cannot be achieved. In contrast to simpler substances, the inherent heterogeneity in the structure of biological macromolecules makes traceability to a unique chemical substance difficult to achieve, although it is possible as argued here by a consensus definition. In addition to structural heterogeneity, material heterogeneity or "purity," as expressed by the absence of contaminating substances, presents a challenge of perhaps greater magnitude. The potency of even extremely small amounts of contaminating substances in biological processes places great demand on the sensitivity of the analytical methods used to detect and quantify the contaminants, and, when a contaminant is below the limit of detection, a biological assay that detects an effect of the contaminant will require some further characterization. Because of the impossibility of "proving" the absence (nonexistence) of a trace contaminant, and the existence of multiple substrates, e.g., as noted for the enzyme thrombin, the possibility of discovery of a previously unidentified contaminant must always be entertained and, when evidence suggests, investigated.

Metrological traceability extends beyond the limited portion of the chain illustrated in Fig. 1 [142]. In fact, the utility of the traceability chain lies in obtaining comparability of measurement results from procedures for routine use because of the employment of those results in medical and commercial decision making.

Modifications to the traceability chain may be required, but the modified chain must retain its link to fundamental SI units: kilogram, mole, and katal. The hierarchy of measurement steps necessary for assigning the measurand value to the final material and using the material with methods used in routine laboratory medicine must be unambiguous, with the caveats related to influence quantities in the sample analyzed in a routine method.

\subsection{Metrological Confidence-Recognition of Inherent Limitations for Biological Measurands}

In situations involving macromolecules of biological origin, classical assessment of measurement uncertainty may not be practical. While uncertainties can be quantitatively estimated for the results of 
measurements of well-defined measurands, the fitness of a complex multifunctional material for a specific purpose may also depend on poorly defined properties and interactions that can only be qualitatively assessed. As an alternative to metrological uncertainty, the concept of metrological confidence can be employed as a means of evaluating the fitness of a material or measurement procedure. This view is concordant with that of the Intergovernmental Panel on Climate Change Working Group III (IPCC WG III): "Where uncertainty is assessed qualitatively, it is characterized by providing a relative sense of the amount and quality of evidence (that is, information from theory, observations or models indicating whether a belief or proposition is true or valid) and the degree of agreement (that is, the level of concurrence in the literature on a particular finding). This approach is used by WG III through a series of self-explanatory terms such as: high agreement, much evidence; high agreement, medium evidence; medium agreement, medium evidence; etc." [143].

Metrological confidence (Fig. 16) in the reference system for thrombin can be asserted from the following considerations:

(1) General concordance in the sequence for human $\alpha$-thrombin from multiple methods and crystallographic structures.

(2) Identification of mutations and polymorphisms that are consequential for thrombin's biological activity.

(3) Established methods for purification of the precursor to thrombin that provide evidence for the separation of contaminating substances that influence the measurement of thrombin activity.

(4) Availability of technologies capable of detecting and quantifying contaminants, e.g., protein and peptide MS.

(5) Selection of the substrate, fibrinogen, that utilizes several sites and exosites within the thrombin molecule for recognition, specificity, and catalytic efficiency.

(6) Choice of reaction solution composition and component concentrations that minimize measurement bias and imprecision.

(7) Kinetic characterization of the reaction mechanism that enables detailed characterization of the reference material and the substrate beyond the conditions specified for the measurement procedure.

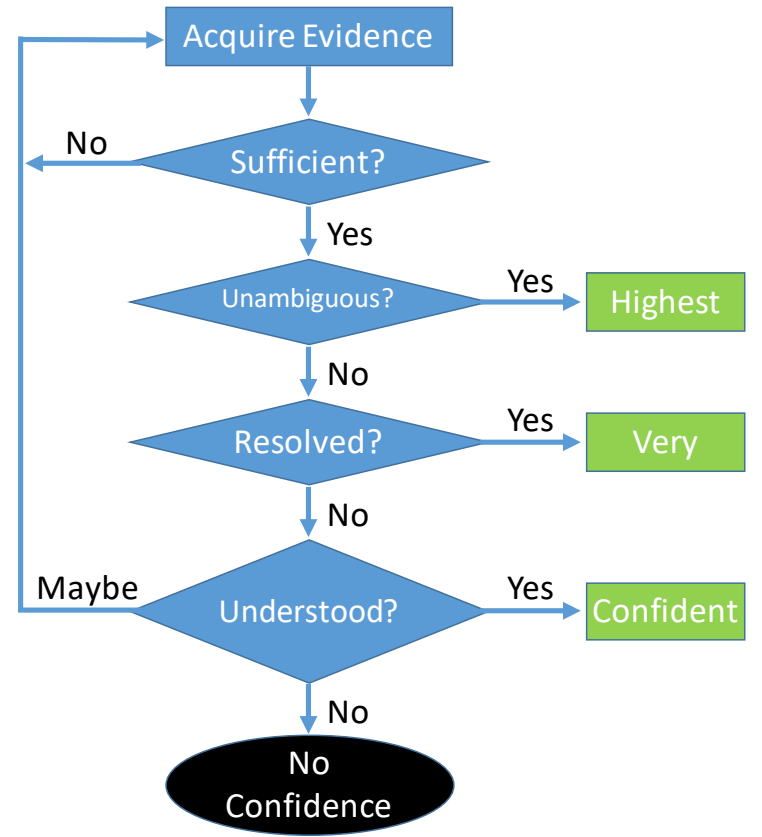

Fig. 16. Metrological confidence - a reference system for thrombin. An evaluation process to enable meaningful interpretation of results when metrological uncertainty cannot be quantitatively estimated is suggested for evaluating the proposed reference system for thrombin. Consensus of the stakeholders who are the intended beneficiaries determines the level of confidence that will be assigned to the reference material and the measurement procedure [144]. 
Reference materials have been provided for measurement of thrombin activity for decades, with advances in understanding and methods for assessment of quality employed with each successive preparation [7]. The geometric mean of the results from a variety of measurement methods widely used by laboratories throughout the world represents a consensus value for units assigned to these reference standards. Dose response behavior is taken to be represented by the log of the response in the assay method versus the log of the concentration of the dilution of the reference materials. The most recent material was compared to both the WHO's 1st International Standard and the NIH's U.S. Standard, Lot J, to produce a single unit for the WHO 2nd International Standard 01/580. In deciding the best value to be assigned to the material, because of the recognized bias that would result from $\beta$ - and $\gamma$-thrombin activity measured by peptide chromogenic substrates, data from chromogenic substrate hydrolysis were excluded [7].

Preparations of thrombin used in research laboratories have been characterized with respect to the unit activity provided by WHO and NIH reference materials. The ratios of activity to protein mass (commonly measured spectrophotometrically) have had specific activities from (3000 to 4000) units/mg protein. By active site titration, these materials have been generally $95 \%$ active (esterolytically active as measured by p-nitrophenyl-guanidinobenzoate burst). International Standard 01/580 is indicated to be $2240 \mathrm{units} / \mathrm{mg}$ [7]. Methods for protein quantification are not indicated, and thus overestimation of protein, which would underestimate the specific activity, is not possible. If the measured protein is "inert" and would not create bias, this international standard might be all $\alpha$-thrombin; this is, however, not determinable from the published data.

Based on information provided in this document, we conclude that the development of both a reference material and reference measurement procedure that are suitably characterized and metrologically traceable for substance amount and proteolytic activity of thrombin is entirely feasible. The production of such a product would be beneficial for calibration and value assignment in both laboratory diagnostic and therapeutic products.

The potential utility of a reference system for thrombin is great. Licensed thrombin products for arresting bleeding are already in use. Some of these are potentially available and might be suitable for secondary reference materials to be used in routine laboratory methods that employ thrombin. Although perhaps brash, we suggest that the lessons learned from the development of this material and method could inform the development of other reference systems, and thus improve measurement comparability for other biological materials of clinical importance. 


\section{Appendix}

Table A1. Thrombin numbering variations for the A ("light") chain.

\begin{tabular}{|c|c|c|c|c|c|}
\hline $\begin{array}{c}\text { UniProt } \\
\text { (Includes Signal, } \\
\text { Propeptide) }\end{array}$ & $\begin{array}{l}\text { Prothrombin Amino- } \\
\text { Terminus, Residue } 1\end{array}$ & $\begin{array}{c}\text { Chymotrypsin } \\
\text { System }\end{array}$ & $\begin{array}{c}\text { One-Letter Amino } \\
\text { Acid Code }\end{array}$ & $\begin{array}{c}\text { Three-Letter Amino } \\
\text { Acid Code }\end{array}$ & $\begin{array}{c}\text { Thrombin Chain } \\
\text { Numbering }\end{array}$ \\
\hline 328 & 285 & $1 \mathrm{H}$ & $\mathrm{T}$ & Thr & 1 \\
\hline 329 & 286 & $1 \mathrm{G}$ & $\mathrm{F}$ & Phe & 2 \\
\hline 330 & 287 & $1 \mathrm{~F}$ & $\mathrm{G}$ & Gly & 3 \\
\hline 331 & 288 & $1 \mathrm{E}$ & S & Ser & 4 \\
\hline 332 & 289 & $1 \mathrm{D}$ & $\mathrm{G}$ & Gly & 5 \\
\hline 333 & 290 & $1 \mathrm{C}$ & E & Glu & 6 \\
\hline 334 & 291 & $1 \mathrm{~B}$ & A & Ala & 7 \\
\hline 335 & 292 & $1 \mathrm{~A}$ & $\mathrm{D}$ & Asp & 8 \\
\hline 336 & 293 & 1 & $\mathrm{C}$ & Cys & 9 \\
\hline 337 & 294 & 2 & $\mathrm{G}$ & Gly & 10 \\
\hline 338 & 295 & 3 & $\mathrm{~L}$ & Leu & 11 \\
\hline 339 & 296 & 4 & $\mathrm{R}$ & Arg & 12 \\
\hline 340 & 297 & 5 & $\mathrm{P}$ & Pro & 13 \\
\hline 341 & 298 & 6 & $\mathrm{~L}$ & Leu & 14 \\
\hline 342 & 299 & 7 & $\mathrm{~F}$ & Phe & 15 \\
\hline 343 & 300 & 8 & E & Glu & 16 \\
\hline 344 & 301 & 9 & K & Lys & 17 \\
\hline 345 & 302 & 10 & $\mathrm{~K}$ & Lys & 18 \\
\hline 346 & 303 & 11 & $\mathrm{~S}$ & Ser & 19 \\
\hline 347 & 304 & 12 & $\mathrm{~L}$ & Leu & 20 \\
\hline 348 & 305 & 13 & E & Glu & 21 \\
\hline 349 & 306 & 14 & D & Asp & 22 \\
\hline 350 & 307 & $14 \mathrm{~A}$ & $\mathrm{~K}$ & Lys & 23 \\
\hline 351 & 308 & $14 \mathrm{~B}$ & $\mathrm{~T}$ & Thr & 24 \\
\hline 352 & 309 & $14 \mathrm{C}$ & E & Glu & 25 \\
\hline 353 & 310 & $14 \mathrm{D}$ & $\mathrm{R}$ & Arg & 26 \\
\hline 354 & 311 & $14 \mathrm{E}$ & E & Glu & 27 \\
\hline 355 & 312 & $14 \mathrm{~F}$ & $\mathrm{~L}$ & Leu & 28 \\
\hline 356 & 313 & $14 \mathrm{G}$ & $\mathrm{L}$ & Leu & 29 \\
\hline 357 & 314 & $14 \mathrm{H}$ & E & Glu & 30 \\
\hline 358 & 315 & $14 \mathrm{I}$ & $\mathrm{S}$ & Ser & 31 \\
\hline 359 & 316 & $14 \mathrm{~J}$ & $\mathrm{Y}$ & Tyr & 32 \\
\hline 360 & 317 & $14 \mathrm{~K}$ & I & Ile & 33 \\
\hline 361 & 318 & $14 \mathrm{~L}$ & D & Asp & 34 \\
\hline 362 & 319 & $14 \mathrm{M}$ & $\mathrm{G}$ & Gly & 35 \\
\hline 363 & 320 & 15 & $\mathrm{R}$ & $\mathrm{Arg}$ & 36 \\
\hline
\end{tabular}




\section{Journal of Research of the National Institute of Standards and Technology}

Table A2. Thrombin numbering variations for the B ("heavy") chain.

UniProt (Includes Signal

Prothrombin Amino-

Chymotrypsin

One-Letter Amin

Three-Letter Amino Thrombin Chain

\begin{tabular}{|c|c|c|c|c|c|}
\hline Propeptide) & Terminus, Residue 1 & System & Acid Code & Acid Code & Numbering \\
\hline 364 & 321 & 16 & I & Ile & 37 \\
\hline 365 & 322 & 17 & $\mathrm{~V}$ & Val & 38 \\
\hline 366 & 323 & 18 & E & Glu & 39 \\
\hline 367 & 324 & 19 & G & Gly & 40 \\
\hline 368 & 325 & 20 & S & Ser & 41 \\
\hline 369 & 326 & 21 & $\mathrm{D}$ & Asp & 42 \\
\hline 370 & 327 & 22 & A & Ala & 43 \\
\hline 371 & 328 & 23 & $\mathrm{E}$ & Glu & 44 \\
\hline 372 & 329 & 24 & I & Ile & 45 \\
\hline 373 & 330 & 25 & G & Gly & 46 \\
\hline 374 & 331 & 26 & M & Met & 47 \\
\hline 375 & 332 & 27 & S & Ser & 48 \\
\hline 376 & 333 & 28 & $\mathrm{P}$ & Pro & 49 \\
\hline 377 & 334 & 29 & W & Trp & 50 \\
\hline 378 & 335 & 30 & Q & Gln & 51 \\
\hline 379 & 336 & 31 & V & Val & 52 \\
\hline 380 & 337 & 32 & $\mathrm{M}$ & Met & 53 \\
\hline 381 & 338 & 33 & $\mathrm{~L}$ & Leu & 54 \\
\hline 382 & 339 & 34 & $\mathrm{~F}$ & Phe & 55 \\
\hline 383 & 340 & 35 & $\mathrm{R}$ & Arg & 56 \\
\hline 384 & 341 & 36 & $\mathrm{~K}$ & Lys & 57 \\
\hline 385 & 342 & $36 \mathrm{~A}$ & $\mathrm{~S}$ & Ser & 58 \\
\hline 386 & 343 & 37 & $\mathrm{P}$ & Pro & 59 \\
\hline 387 & 344 & 38 & $\mathrm{Q}$ & Gln & 60 \\
\hline 388 & 345 & 39 & $\mathrm{E}$ & Glu & 61 \\
\hline 389 & 346 & 40 & $\mathrm{~L}$ & Leu & 62 \\
\hline 390 & 347 & 41 & $\mathrm{~L}$ & Leu & 63 \\
\hline 391 & 348 & 42 & $\mathrm{C}$ & Cys & 64 \\
\hline 392 & 349 & 43 & G & Gly & 65 \\
\hline 393 & 350 & 44 & A & Ala & 66 \\
\hline 394 & 351 & 45 & $\mathrm{~S}$ & Ser & 67 \\
\hline 395 & 352 & 46 & $\mathrm{~L}$ & Leu & 68 \\
\hline 396 & 353 & 47 & I & Ile & 69 \\
\hline 397 & 354 & 48 & $\mathrm{~S}$ & Ser & 70 \\
\hline 398 & 355 & 49 & $\mathrm{D}$ & Asp & 71 \\
\hline 399 & 356 & 50 & $\mathrm{R}$ & Arg & 72 \\
\hline 400 & 357 & 51 & W & Trp & 73 \\
\hline 401 & 358 & 52 & $\mathrm{~V}$ & Val & 74 \\
\hline 402 & 359 & 53 & $\mathrm{~L}$ & Leu & 75 \\
\hline 403 & 360 & 54 & $\mathrm{~T}$ & Thr & 76 \\
\hline 404 & 361 & 55 & A & Ala & 77 \\
\hline 405 & 362 & 56 & A & Ala & 78 \\
\hline 406 & 363 & 57 & $\mathrm{H}$ & Hs & 79 \\
\hline 407 & 364 & 58 & $\mathrm{C}$ & Cys & 80 \\
\hline 408 & 365 & 59 & $\mathrm{~L}$ & Leu & 81 \\
\hline 409 & 366 & 60 & $\mathrm{~L}$ & Leu & 82 \\
\hline 410 & 367 & $60 \mathrm{~A}$ & $\mathrm{Y}$ & Tyr & 83 \\
\hline 411 & 368 & $60 \mathrm{~B}$ & $\mathrm{P}$ & Pro & 84 \\
\hline 412 & 369 & $60 \mathrm{C}$ & $\mathrm{P}$ & Pro & 85 \\
\hline 413 & 370 & $60 \mathrm{D}$ & W & Trp & 86 \\
\hline 414 & 371 & $60 \mathrm{E}$ & $\mathrm{D}$ & Asp & 87 \\
\hline 415 & 372 & $60 \mathrm{~F}$ & $\mathrm{~K}$ & Lys & 88 \\
\hline 416 & 373 & $60 \mathrm{G}$ & $\mathrm{N}$ & Asn & 89 \\
\hline 417 & 374 & $60 \mathrm{H}$ & $\mathrm{F}$ & Phe & 90 \\
\hline 418 & 375 & $60 \mathrm{I}$ & $\mathrm{T}$ & Thr & 91 \\
\hline 419 & 376 & 61 & E & Glu & 92 \\
\hline
\end{tabular}




\section{Journal of Research of the National Institute of Standards and Technology}

\begin{tabular}{|c|c|c|c|c|c|}
\hline $\begin{array}{c}\text { UniProt } \\
\text { (Includes Signal, } \\
\text { Propeptide) }\end{array}$ & $\begin{array}{l}\text { Prothrombin Amino- } \\
\text { Terminus, Residue } 1\end{array}$ & $\begin{array}{c}\text { Chymotrypsin } \\
\text { System }\end{array}$ & $\begin{array}{c}\text { One-Letter Amino } \\
\text { Acid Code }\end{array}$ & $\begin{array}{c}\text { Three-Letter Amino } \\
\text { Acid Code }\end{array}$ & $\begin{array}{c}\text { Thrombin Chain } \\
\text { Numbering }\end{array}$ \\
\hline 420 & 377 & 62 & $\mathrm{~N}$ & Asn & 93 \\
\hline 421 & 378 & 63 & $\mathrm{D}$ & Asp & 94 \\
\hline 422 & 379 & 64 & $\mathrm{~L}$ & Leu & 95 \\
\hline 423 & 380 & 65 & $\mathrm{~L}$ & Leu & 96 \\
\hline 424 & 381 & 66 & $\mathrm{~V}$ & Val & 97 \\
\hline 425 & 382 & 67 & $\mathrm{R}$ & Arg & 98 \\
\hline 426 & 383 & 68 & I & Ile & 99 \\
\hline 427 & 384 & 69 & $\mathrm{G}$ & Gly & 100 \\
\hline 428 & 385 & 70 & $\mathrm{~K}$ & Lys & 101 \\
\hline 429 & 386 & 71 & $\mathrm{H}$ & His & 102 \\
\hline 430 & 387 & 72 & $\mathrm{~S}$ & Ser & 103 \\
\hline 431 & 388 & 73 & $\mathrm{R}$ & Arg & 104 \\
\hline 432 & 389 & 74 & $\mathrm{~T}$ & Thr & 105 \\
\hline 433 & 390 & 75 & $\mathrm{R}$ & Arg & 106 \\
\hline 434 & 391 & 76 & $\mathrm{Y}$ & Tyr & 107 \\
\hline 435 & 392 & 77 & E & Glu & 108 \\
\hline 436 & 393 & $77 \mathrm{~A}$ & $\mathrm{R}$ & Arg & 109 \\
\hline 437 & 394 & 78 & $\mathrm{~N}$ & Asn & 110 \\
\hline 438 & 395 & 79 & I & Ile & 111 \\
\hline 439 & 396 & 80 & $\mathrm{E}$ & Glu & 112 \\
\hline 440 & 397 & 81 & $\mathrm{~K}$ & Lys & 113 \\
\hline 441 & 398 & 82 & I & Ile & 114 \\
\hline 442 & 399 & 83 & $\mathrm{~S}$ & Ser & 115 \\
\hline 443 & 400 & 84 & $\mathrm{M}$ & Met & 116 \\
\hline 444 & 401 & 85 & $\mathrm{~L}$ & Leu & 117 \\
\hline 445 & 402 & 86 & $\mathrm{E}$ & Glu & 118 \\
\hline 446 & 403 & 87 & K & Lys & 119 \\
\hline 447 & 404 & 88 & I & Ile & 120 \\
\hline 448 & 405 & 89 & $\mathrm{Y}$ & Tyr & 121 \\
\hline 449 & 406 & 90 & I & Ile & 122 \\
\hline 450 & 407 & 91 & $\mathrm{H}$ & His & 123 \\
\hline 451 & 408 & 92 & $\mathrm{P}$ & Pro & 124 \\
\hline 452 & 409 & 93 & $\mathrm{R}$ & Arg & 125 \\
\hline 453 & 410 & 94 & $\mathrm{Y}$ & Tyr & 126 \\
\hline 454 & 411 & 95 & $\mathrm{~N}$ & Asn & 127 \\
\hline 455 & 412 & 96 & W & Trp & 128 \\
\hline 456 & 413 & 97 & $\mathrm{R}$ & Arg & 129 \\
\hline 457 & 414 & $97 \mathrm{~A}$ & E & Glu & 130 \\
\hline 458 & 415 & 98 & $\mathrm{~N}$ & Asn & 131 \\
\hline 459 & 416 & 99 & $\mathrm{~L}$ & Leu & 132 \\
\hline 460 & 417 & 100 & $\mathrm{D}$ & Asp & 133 \\
\hline 461 & 418 & 101 & $\mathrm{R}$ & Arg & 134 \\
\hline 462 & 419 & 102 & $\mathrm{D}$ & Asp & 135 \\
\hline 463 & 420 & 103 & I & Ile & 136 \\
\hline 464 & 421 & 104 & A & Ala & 137 \\
\hline 465 & 422 & 105 & $\mathrm{~L}$ & Leu & 138 \\
\hline 466 & 423 & 106 & $\mathrm{M}$ & Met & 139 \\
\hline 467 & 424 & 107 & $\mathrm{~K}$ & Lys & 140 \\
\hline 468 & 425 & 108 & $\mathrm{~L}$ & Leu & 141 \\
\hline 469 & 426 & 109 & $\mathrm{~K}$ & Lys & 142 \\
\hline 470 & 427 & 110 & $\mathrm{~K}$ & Lys & 143 \\
\hline 471 & 428 & 111 & $\mathrm{P}$ & Pro & 144 \\
\hline 472 & 429 & 112 & $\mathrm{~V}$ & Val & 145 \\
\hline 473 & 430 & 113 & A & Ala & 146 \\
\hline 474 & 431 & 114 & $\mathrm{~F}$ & Phe & 147 \\
\hline 475 & 432 & 115 & $\mathrm{~S}$ & Ser & 148 \\
\hline 476 & 433 & 116 & $\mathrm{D}$ & Asp & 149 \\
\hline 477 & 434 & 117 & $\mathrm{Y}$ & Tyr & 150 \\
\hline 478 & 435 & 118 & I & Ile & 151 \\
\hline
\end{tabular}




\section{Journal of Research of the National Institute of Standards and Technology}

\begin{tabular}{|c|c|c|c|c|c|}
\hline $\begin{array}{c}\text { UniProt } \\
\text { (Includes Signal, } \\
\text { Propeptide) }\end{array}$ & $\begin{array}{l}\text { Prothrombin Amino- } \\
\text { Terminus, Residue } 1\end{array}$ & $\begin{array}{l}\text { Chymotrypsin } \\
\text { System }\end{array}$ & $\begin{array}{c}\text { One-Letter Amino } \\
\text { Acid Code }\end{array}$ & $\begin{array}{l}\text { Three-Letter Amino } \\
\text { Acid Code }\end{array}$ & $\begin{array}{c}\text { Thrombin Chain } \\
\text { Numbering }\end{array}$ \\
\hline 479 & 436 & 119 & $\mathrm{H}$ & His & 152 \\
\hline 480 & 437 & 120 & $\mathrm{P}$ & Pro & 153 \\
\hline 481 & 438 & 121 & V & Val & 154 \\
\hline 482 & 439 & 122 & $\mathrm{C}$ & Cys & 155 \\
\hline 483 & 440 & 123 & $\mathrm{~L}$ & Leu & 156 \\
\hline 484 & 441 & 124 & $\mathrm{P}$ & Pro & 157 \\
\hline 485 & 442 & 125 & $\mathrm{D}$ & Asp & 158 \\
\hline 486 & 443 & 126 & $\mathrm{R}$ & Arg & 159 \\
\hline 487 & 444 & 127 & $\mathrm{E}$ & Glu & 160 \\
\hline 488 & 445 & 128 & $\mathrm{~T}$ & Thr & 161 \\
\hline 489 & 446 & 129 & A & Ala & 162 \\
\hline 490 & 447 & $129 \mathrm{~A}$ & A & Ala & 163 \\
\hline 491 & 448 & $129 \mathrm{~B}$ & $\mathrm{~S}$ & Ser & 164 \\
\hline 492 & 449 & $129 \mathrm{C}$ & $\mathrm{L}$ & Leu & 165 \\
\hline 493 & 450 & 130 & $\mathrm{~L}$ & Leu & 166 \\
\hline 494 & 451 & 131 & Q & Gln & 167 \\
\hline 495 & 452 & 132 & A & Ala & 168 \\
\hline 496 & 453 & 133 & G & Gly & 169 \\
\hline 497 & 454 & 134 & $\mathrm{Y}$ & Tyr & 170 \\
\hline 498 & 455 & 135 & $\mathrm{~K}$ & Lys & 171 \\
\hline 499 & 456 & 136 & $\mathrm{G}$ & Gly & 172 \\
\hline 500 & 457 & 137 & $\mathrm{R}$ & Arg & 173 \\
\hline 501 & 458 & 138 & V & Val & 174 \\
\hline 502 & 459 & 139 & $\mathrm{~T}$ & Thr & 175 \\
\hline 503 & 460 & 140 & $\mathrm{G}$ & Gly & 176 \\
\hline 504 & 461 & 141 & W & Trp & 177 \\
\hline 505 & 462 & 142 & $\mathrm{G}$ & Gly & 178 \\
\hline 506 & 463 & 143 & $\mathrm{~N}$ & Asn & 179 \\
\hline 507 & 464 & 144 & $\mathrm{~L}$ & Leu & 180 \\
\hline 508 & 465 & 145 & $\mathrm{~K}$ & Lys & 181 \\
\hline 509 & 466 & 146 & E & Glu & 182 \\
\hline 510 & 467 & 147 & $\mathrm{~T}$ & Thr & 183 \\
\hline 511 & 468 & 148 & W & Trp & 184 \\
\hline 512 & 469 & 149 & $\mathrm{~T}$ & Thr & 185 \\
\hline 513 & 470 & $149 \mathrm{~A}$ & A & Ala & 186 \\
\hline 514 & 471 & $149 \mathrm{~B}$ & $\mathrm{~N}$ & Asn & 187 \\
\hline 515 & 472 & $149 \mathrm{C}$ & V & Val & 188 \\
\hline 516 & 473 & $149 \mathrm{D}$ & G & Gl & 189 \\
\hline 517 & 474 & $149 \mathrm{E}$ & $\mathrm{K}$ & Lys & 190 \\
\hline 518 & 475 & 150 & $\mathrm{G}$ & Gly & 191 \\
\hline 519 & 476 & 151 & Q & Gln & 192 \\
\hline 520 & 477 & 152 & $\mathrm{P}$ & Pro & 193 \\
\hline 521 & 478 & 153 & $\mathrm{~S}$ & Ser & 194 \\
\hline 522 & 479 & 154 & $\mathrm{~V}$ & Val & 195 \\
\hline 523 & 480 & 155 & $\mathrm{~L}$ & Leu & 196 \\
\hline 524 & 481 & 156 & $\mathrm{Q}$ & Gln & 197 \\
\hline 525 & 482 & 157 & V & Val & 198 \\
\hline 526 & 483 & 158 & $\mathrm{~V}$ & Val & 199 \\
\hline 527 & 484 & 159 & $\mathrm{~N}$ & Asn & 200 \\
\hline 528 & 485 & 160 & $\mathrm{~L}$ & Leu & 201 \\
\hline 529 & 486 & 161 & $\mathrm{P}$ & Pro & 202 \\
\hline 530 & 487 & 162 & I & Ile & 203 \\
\hline 531 & 488 & 163 & V & Val & 204 \\
\hline 532 & 489 & 164 & $\mathrm{E}$ & Glu & 205 \\
\hline 533 & 490 & 165 & $\mathrm{R}$ & Arg & 206 \\
\hline 534 & 491 & 166 & $\mathrm{P}$ & Pro & 207 \\
\hline 535 & 492 & 167 & $\mathrm{~V}$ & Val & 208 \\
\hline 536 & 493 & 168 & $\mathrm{C}$ & Cys & 209 \\
\hline 537 & 494 & 169 & $\mathrm{~K}$ & Lys & 210 \\
\hline
\end{tabular}




\section{Journal of Research of the National Institute of Standards and Technology}

\begin{tabular}{|c|c|c|c|c|c|}
\hline $\begin{array}{c}\text { UniProt } \\
\text { (Includes Signal, } \\
\text { Propeptide) }\end{array}$ & $\begin{array}{l}\text { Prothrombin Amino- } \\
\text { Terminus, Residue } 1\end{array}$ & $\begin{array}{c}\text { Chymotrypsin } \\
\text { System }\end{array}$ & $\begin{array}{c}\text { One-Letter Amino } \\
\text { Acid Code }\end{array}$ & $\begin{array}{l}\text { Three-Letter Amino } \\
\text { Acid Code }\end{array}$ & $\begin{array}{c}\text { Thrombin Chain } \\
\text { Numbering }\end{array}$ \\
\hline 538 & 495 & 170 & $\mathrm{D}$ & Asp & 211 \\
\hline 539 & 496 & 171 & S & Ser & 212 \\
\hline 540 & 497 & 172 & $\mathrm{~T}$ & Thr & 213 \\
\hline 541 & 498 & 173 & $\mathrm{R}$ & Arg & 214 \\
\hline 542 & 499 & 174 & I & Ile & 215 \\
\hline 543 & 500 & 175 & $\mathrm{R}$ & Arg & 216 \\
\hline 544 & 501 & 176 & I & Ile & 217 \\
\hline 545 & 502 & 177 & $\mathrm{~T}$ & Thr & 218 \\
\hline 546 & 503 & 178 & $\mathrm{D}$ & Asp & 219 \\
\hline 547 & 504 & 179 & $\mathrm{~N}$ & Asn & 220 \\
\hline 548 & 505 & 180 & $\mathrm{M}$ & Met & 221 \\
\hline 549 & 506 & 181 & $\mathrm{~F}$ & Phe & 222 \\
\hline 550 & 507 & 182 & $\mathrm{C}$ & Cys & 223 \\
\hline 551 & 508 & 183 & A & Ala & 224 \\
\hline 552 & 509 & 184 & G & Gly & 225 \\
\hline 553 & 510 & $184 \mathrm{~A}$ & $\mathrm{Y}$ & Tyr & 226 \\
\hline 554 & 511 & 185 & $\mathrm{~K}$ & Lys & 227 \\
\hline 555 & 512 & 186 & $\mathrm{P}$ & Pro & 228 \\
\hline 556 & 513 & $186 \mathrm{~A}$ & D & Asp & 229 \\
\hline 557 & 514 & $186 \mathrm{~B}$ & E & Glu & 230 \\
\hline 558 & 515 & $186 \mathrm{C}$ & $\mathrm{G}$ & Gly & 231 \\
\hline 559 & 516 & $186 \mathrm{D}$ & $\mathrm{K}$ & Lys & 232 \\
\hline 560 & 517 & 187 & $\mathrm{R}$ & Arg & 233 \\
\hline 561 & 518 & 188 & $\mathrm{G}$ & Gly & 234 \\
\hline 562 & 519 & 189 & D & Asp & 235 \\
\hline 563 & 520 & 190 & A & Ala & 236 \\
\hline 564 & 521 & 191 & $\mathrm{C}$ & Cys & 237 \\
\hline 565 & 522 & 192 & $\mathrm{E}$ & Glu & 238 \\
\hline 566 & 523 & 193 & $\mathrm{G}$ & Gly & 239 \\
\hline 567 & 524 & 194 & D & Asp & 240 \\
\hline 568 & 525 & 195 & $\mathrm{~S}$ & Ser & 241 \\
\hline 569 & 526 & 196 & $\mathrm{G}$ & Gly & 242 \\
\hline 570 & 527 & 197 & G & Gly & 243 \\
\hline 571 & 528 & 198 & $\mathrm{P}$ & Pro & 244 \\
\hline 572 & 529 & 199 & $\mathrm{~F}$ & Phe & 245 \\
\hline 573 & 530 & 200 & V & Val & 246 \\
\hline 574 & 531 & 201 & M & Met & 247 \\
\hline 575 & 532 & 202 & $\mathrm{~K}$ & Lys & 248 \\
\hline 576 & 533 & 203 & $\mathrm{~S}$ & Ser & 249 \\
\hline 577 & 534 & 204 & $\mathrm{P}$ & Pro & 250 \\
\hline 578 & 535 & $204 \mathrm{~A}$ & $\mathrm{~F}$ & Phe & 251 \\
\hline 579 & 536 & $204 \mathrm{~B}$ & $\mathrm{~N}$ & Asn & 252 \\
\hline 580 & 537 & 205 & $\mathrm{~N}$ & Asn & 253 \\
\hline 581 & 538 & 206 & $\mathrm{R}$ & Arg & 254 \\
\hline 582 & 539 & 207 & W & Trp & 255 \\
\hline 583 & 540 & 208 & Y & Tyr & 256 \\
\hline 584 & 541 & 209 & Q & Gln & 257 \\
\hline 585 & 542 & 210 & $\mathrm{M}$ & Met & 258 \\
\hline 586 & 543 & 211 & G & Gly & 259 \\
\hline 587 & 544 & 212 & I & Ile & 260 \\
\hline 588 & 545 & 213 & V & Val & 261 \\
\hline 589 & 546 & 214 & $\mathrm{~S}$ & Ser & 262 \\
\hline 590 & 547 & 215 & W & Trp & 263 \\
\hline 591 & 548 & 216 & $\mathrm{G}$ & Gly & 264 \\
\hline 592 & 549 & 217 & $\mathrm{E}$ & Glu & 265 \\
\hline 593 & 550 & 218 & $\mathrm{G}$ & Gly & 266 \\
\hline 594 & 551 & 219 & $\mathrm{C}$ & Cys & 267 \\
\hline 595 & 552 & 220 & D & Asp & 268 \\
\hline 596 & 553 & 221 & $\mathrm{R}$ & Arg & 269 \\
\hline
\end{tabular}




\section{Journal of Research of the National Institute of Standards and Technology}

\begin{tabular}{|c|c|c|c|c|c|}
\hline $\begin{array}{c}\text { UniProt } \\
\text { (Includes Signal, } \\
\text { Propeptide) }\end{array}$ & $\begin{array}{l}\text { Prothrombin Amino- } \\
\text { Terminus, Residue } 1\end{array}$ & $\begin{array}{c}\text { Chymotrypsin } \\
\text { System }\end{array}$ & $\begin{array}{c}\text { One-Letter Amino } \\
\text { Acid Code }\end{array}$ & $\begin{array}{c}\text { Three-Letter Amino } \\
\text { Acid Code }\end{array}$ & $\begin{array}{c}\text { Thrombin Chain } \\
\text { Numbering }\end{array}$ \\
\hline 597 & 554 & 222 & $\mathrm{D}$ & Asp & 270 \\
\hline 598 & 555 & 223 & $\mathrm{G}$ & Gly & 271 \\
\hline 599 & 556 & 224 & $\mathrm{~K}$ & Lys & 272 \\
\hline 600 & 557 & 225 & Y & Tyr & 273 \\
\hline 601 & 558 & 226 & $\mathrm{G}$ & Gly & 274 \\
\hline 602 & 559 & 227 & $\mathrm{~F}$ & Phe & 275 \\
\hline 603 & 560 & 228 & $\mathrm{Y}$ & Tyr & 276 \\
\hline 604 & 561 & 229 & $\mathrm{~T}$ & Thr & 277 \\
\hline 605 & 562 & 230 & $\mathrm{H}$ & His & 278 \\
\hline 606 & 563 & 231 & $\mathrm{~V}$ & Val & 279 \\
\hline 607 & 564 & 232 & $\mathrm{~F}$ & Phe & 280 \\
\hline 608 & 565 & 233 & $\mathrm{R}$ & Arg & 281 \\
\hline 609 & 566 & 234 & L & Leu & 282 \\
\hline 610 & 567 & 235 & $\mathrm{~K}$ & Lys & 283 \\
\hline 611 & 568 & 236 & $\mathrm{~K}$ & Lys & 284 \\
\hline 612 & 569 & 237 & W & $\operatorname{Trp}$ & 285 \\
\hline 613 & 570 & 238 & I & Ile & 286 \\
\hline 614 & 571 & 239 & Q & Gln & 287 \\
\hline 615 & 572 & 240 & $\mathrm{~K}$ & Lys & 288 \\
\hline 616 & 573 & 241 & V & Val & 289 \\
\hline 617 & 574 & 242 & I & Ile & 290 \\
\hline 618 & 575 & 243 & $\mathrm{D}$ & Asp & 291 \\
\hline 619 & 576 & 244 & Q & Gln & 292 \\
\hline 620 & 577 & 245 & F & Phe & 293 \\
\hline 621 & 578 & 246 & $\mathrm{G}$ & Gly & 294 \\
\hline 622 & 579 & 247 & E & Glu & 295 \\
\hline
\end{tabular}

\section{References}

[1] Marcum JA (1998) Defending the priority of 'remarkable researches': The discovery of fibrin ferment. History and Philosophy of the Life Sciences 20(1):51-76. PMID: 10069080

[2] Seegers WH, Warner ED, Brinkhous KM, Smith HP (1939) The use of purified thrombin as an hemostatic agent. Science 89(2300):86. https://doi.org/10.1126/science.89.2300.86

[3] Yin ET, Wessler S (1968) Bovine thrombin and activated factor X. Separation and purification. Journal of Biological Chemistry 243(1):112-117. http://www.jbc.org/content/243/1/112.long

[4] Kerwin DM, Milstone JH (1967) Removal of thrombokinase from commercial thrombin. Thrombosis et Diathesis Haemorrhagica 17(1-2):247-255. PMID: 5584956

[5] Cohn EJ, Strong LE, Hughes WL, Mulford DJ, Ashworth JN, Melin M, Taylor HL (1946) Preparation and properties of serum and plasma proteins. IV. A system for the separation into fractions of the protein and lipoprotein components of biological tissues and fluids. Journal of the American Chemical Society 68(3):459-475. https://doi.org/10.1021/ja01207a034

[6] Gaffney PJ, Heath AB, Fenton JW 2nd (1992) A collaborative study to establish an international standard for alpha-thrombin. Thrombosis and Haemostasis 67(4):424-427. https://doi.org/10.1055/s-0038-1648464

[7] Whitton C, Sands D, Lee T, Chang A, Longstaff C (2005) A reunification of the US ("NIH") and International Unit into a single standard for thrombin. Thrombosis and Haemostasis 93(2):261-266. https://doi.org/10.1160/TH04-10-0677

[8] Berman HM, Westbrook J, Feng Z, Gilliland G, Bhat TN, Weissig H, Shindyalov IN, Bourne PE (2000) The Protein Data Bank. Nucleic Acids Research 28(1):235-242. https://doi.org/10.1093/nar/28.1.235

[9] Yonemura H, Imamura T, Soejima K, Nakahara Y, Morikawa W, Ushio Y, Kamachi Y, Nakatake H, Sugawara K, Nakagaki T, Nozaki C (2004) Preparation of recombinant alpha-thrombin: High-level expression of recombinant human prethrombin-2 and its activation by recombinant ecarin. Journal of Biochemistry 135(5):577-582. https://doi.org/10.1093/jb/mvh070

[10] Russo G, Gast A, Schlaeger E-J, Angiolollo A, Pietropaolo C (1997) Stable expression and purification of a secreted human recombinant prethrombin-2 and its activation to thrombin. Protein Expression and Purification 10(2): 214-225. https://doi.org/10.1006/prep.1997.0733

[11] U.S. Food \& Drug Administration (2018) RECOTHROM, Thrombin Topical (Recombinant) (U.S. Food \& Drug Administration, Washington, D.C.). Available at https://www.fda.gov/vaccines-blood-biologics/approved-blood-products/recothrom

[12] Pirie NW (1940) The criteria of purity used in the study of large molecules of biological origin. Biological Reviews of the Cambridge Philosophical Society 16(4):28. https://doi.org/10.1111/j.1469-185X.1940.tb00945.x 
[13] Moss GP (1992) Recommendations on Biochemical \& Organic Nomenclature, Symbols \& Terminology (International Union of Biochemistry and Molecular Biology and School of Biological and Chemical Sciences, Queen Mary, University of London, Mile End Road, London, E1 4NS, UK). Available at https://www.qmul.ac.uk/sbcs/iubmb/enzume

[14] Hartley BS (1970) Homologies in serine proteinases. Philosophical Transactions of the Royal Society 257:77-87. https://doi.org/10.1098/rstb.1970.0010

[15] Bing DH, Feldmann RJ, Fenton JW 2nd (1986) Structure-function relationships of thrombin based on the computer-generated threedimensional model of the B chain of bovine thrombin. Annals of the New York Academy of Sciences 485:104-119. https://doi.org/10.1111/j.1749-6632.1986.tb34572.x

[16] Bing DH, Laura R, Robison DJ, Furie B, Furie BC, Feldmann RJ (1981) A computer-generated three-dimensional model of the B chain of bovine alpha-thrombin. Annals of the New York Academy of Sciences 370:496-510. https://doi.org/10.1111/j.1749-6632.1981.tb29758.x

[17] Davie EW, Fujikawa K (1975) Basic mechanisms in blood coagulation. Annual Review of Biochemistry 44:799-829. https://doi.org/10.1146/annurev.bi.44.070175.004055

[18] Bing DH, Cory M, Fenton JW 2nd (1977) Exo-site affinity labeling of human thrombins. Similar labeling on the A chain and B chain/fragments of clotting alpha- and nonclotting gamma/beta-thrombins. Journal of Biological Chemistry 252(22):8027-8034. http://www.jbc.org/content/252/22/8027.long

[19] Sonder SA, Fenton JW 2nd (1983) Differential inactivation of human and bovine alpha-thrombins by exosite affinity-labeling reagents. Thrombosis Research 32(6):623-629. https://doi.org/10.1016/0049-3848(83)90064-6

[20] Bock PE, Panizzi P, Verhamme IM (2007) Exosites in the substrate specificity of blood coagulation reactions. Journal of Thrombosis and Haemostasis 5(Suppl 1):81-94. https://doi.org/10.1111/j.1538-7836.2007.02496.x

[21] Gaboriaud C, Serre L, Guy-Crotte O, Forest E, Fontecilla-Camps JC (1996) Crystal structure of human trypsin 1: Unexpected phosphorylation of Tyr151. Journal of Molecular Biology 259(5):995-1010. https://doi.org/10.1006/jmbi.1996.0376

[22] Bode W, Mayr I, Baumann U, Huber R, Stone SR, Hofsteenge J (1989) The refined 1.9 A crystal structure of human alpha-thrombin: Interaction with D-Phe-Pro-Arg chloromethylketone and significance of the Tyr-Pro-Pro-Trp insertion segment. EMBO Journal 8(11):3467-3475. https://doi.org/10.1002/j.1460-2075.1989.tb08511.x

[23] The UniProt Consortium (2015) UniProt: A hub for protein information. Nucleic Acids Research 43(D1):D204-D212. https://doi.org/10.1093/nar/gku989

[24] Degen SJF, MacGillivray RT, Davie EW (1983) Characterization of the complementary deoxyribonucleic acid and gene coding for human prothrombin. Biochemistry 22(9):2087-2097. https://doi.org/10.1021/bi00278a00819

[25] Degen SJF, Davie EW (1987) Nucleotide sequence of the gene for human prothrombin. Biochemistry 26(19):6165-6177. https://doi.org/10.1021/bi00393a033

[26] Jackson CM, Nemerson Y (1980) Blood coagulation. Annual Review of Biochemistry 49:765-811. https://doi.org/10.1146/annurev.bi.49.070180.004001

[27] Bode W, Turk D, Karshikov A (1992) The refined 1.9-A X-ray crystal structure of D-Phe-Pro-Arg chloromethylketone-inhibited human alpha-thrombin: Structure analysis, overall structure, electrostatic properties, detailed active-site geometry, and structurefunction relationships. Protein Science 1(4):426-471. https://doi.org/10.1002/pro.5560010402

[28] Skrzypczak-Jankun E, Rydel TJ, Tulinsky A, Fenton Ii JW, Mann KG (1989) Human d-Phe-Pro-Arg-CH2- $\alpha$-thrombin crystallization and diffraction data. Journal of Molecular Biology 206(4):755-757. https://doi.org/10.1016/0022-2836(89)90582-2

[29] Chang J-Y (1983) The functional domain of hirudin, a thrombin-specific inhibitor. FEBS Letters 164(2):307-313. https://doi.org/10.1016/0014-5793(83)80307-x

[30] Fenton JW 2nd, Bing DH 1986) Thrombin active-site regions. Seminars in Thrombosis and Hemostasis 12(3):200-208. https://doi.org/10.1055/s-2007-1003551

[31] Fenton JW 2nd (1989) Thrombin interactions with hirudin. Seminars in Thrombosis and Hemostasis 15(3):265-268. https://doi.org/10.1055/s-2007-1002718

[32] Markwardt F (1956) Studies on the mechanism of the anticoagulant effect of hirudin. Naunyn-Schmiedeberg's Archives of Pharmacology 229(4):389-399. PMID: 13387797

[33] Markwardt F, Walsmann P (1958) The reaction between hirudin and thrombin. Hoppe-Seyler's Zeitschrift für Physiologische Chemie 312(1-3):85-98. PMID: 13598405

[34] Markwardt F, Schafer G, Topfer H, Walsmann P (1967) Isolation of hiruin from the medicinal leech. Die Pharmazie 22(6):239-241. PMID: 5599832

[35] Markwardt F (1988) The comeback of hirudin—An old-established anticoagulant agent. Folia Haematologica 115(1-2):10-23. PMID: 2459000

[36] Rydel TJ, Ravichandran KG, Tulinsky A, Bode W, Huber R, Roitsch C, Fenton JW 2nd (1990) The structure of a complex of recombinant hirudin and human alpha-thrombin. Science 249(4966):277-280. https://doi.org/10.1126/science.2374926

[37] Grutter MG, Priestle JP, Rahuel J, Grossenbacher H, Bode W, Hofsteenge J, Stone SR (1990) Crystal structure of the thrombinhirudin complex: A novel mode of serine protease inhibition. EMBO Journal 9(8):2361-2365. https://doi.org/10.1002/j.1460-2075.1990.tb07410.x

[38] Ayala YM, Vindigni A, Nayal M, Spolar RS, Record MT Jr, Di Cera E (1995) Thermodynamic investigation of hirudin binding to the slow and fast forms of thrombin: Evidence for folding transitions in the inhibitor and protease coupled to binding. Journal of Molecular Biology 253(5):787-798. https://doi.org/10.1006/jmbi.1995.0591

[39] Stone SR, Hofsteenge J (1986) Kinetics of the inhibition of thrombin by hirudin. Biochemistry 25(16):4622-4628. https://doi.org/10.1021/bi00364a025 
[40] Braun PJ, Dennis S, Hofsteenge J, Stone SR (1988) Use of site-directed mutagenesis to investigate the basis for the specificity of hirudin. Biochemistry 27(17):6517-6522. https://doi.org/10.1021/bi00417a048

[41] Priestle JP, Rahuel J, Rink H, Tones M, Grutter MG (1993) Changes in interactions in complexes of hirudin derivatives and human alpha-thrombin due to different crystal forms. Protein Science 2(10):1630-1642. https://doi.org/10.1002/pro.5560021009

[42] Naski MC, Fenton JW 2nd, Maraganore JM, Olson ST, Shafer JA (199) The COOH-terminal domain of hirudin. An exosite-directed competitive inhibitor of the action of alpha-thrombin on fibrinogen. Journal of Biological Chemistry 265(23):13484-13489. http://www.jbc.org/content/265/23/13484.long

[43] Maraganore JM, Fenton JW 2nd (1990) Thrombin inhibition by synthetic hirudin peptides. Advances in Experimental Medicine and Biology 281:177-183. https://doi.org/10.1007/978-1-4615-3806-6_17

[44] Skrzypczak-Jankun E, Carperos VE, Ravichandran KG, Tulinsky A, Westbrook M, Maraganore JM (1991) Structure of the hirugen and hirulog 1 complexes of $\alpha$-thrombin. Journal of Molecular Biology 221:1379-1393. https://doi.org/10.1016/0022-2836(91)90939-4

[45] Fenton JW 2nd, Olson TA, Zabinski MP, Wilner GD (1988) Anion-binding exosite of human alpha-thrombin and fibrin(ogen) recognition. Biochemistry 27(18):7106-7112. https://doi.org/10.1021/bi00418a066

[46] Liu LW, Vu TK, Esmon CT, Coughlin SR (1991) The region of the thrombin receptor resembling hirudin binds to thrombin and alters enzyme specificity. Journal of Biological Chemistry 266(26):16977-16980. Available at http://www.jbc.org/content/266/26/16977.long

[47] Chang AC, Detwiler TC (1991) The reaction of thrombin with platelet-derived nexin requires a secondary recognition site in addition to the catalytic site. Biochemical and Biophysical Research Communications 177(3):1198-1204. https://doi.org/10.1016/0006-291x(91)90668-w

[48] Van Deerlin VMD, Tollefsen DM (1991) The N-terminal acidic domain of heparin cofactor II mediates the inhibition of alpha-thrombin in the presence of glycosaminoglycans. Journal of Biological Chemistry 266(30):20223-20231. Available at http://www.jbc.org/content/266/30/20223.long

[49] Rogers SJ, Pratt CW, Whinna HC, Church FC (1992) Role of thrombin exosites in inhibition by heparin cofactor II. Journal of Biological Chemistry 267(6):3613-3617. Available at http://www.jbc.org/content/267/6/3613.long|

[50] Ye J, Liu LW, Esmon CT, Johnson AE (1992) The fifth and sixth growth factor-like domains of thrombomodulin bind to the anionbinding exosite of thrombin and alter its specificity. Journal of Biological Chemistry 267(16):11023-11028. Available at http://www.jbc.org/content/267/16/11023.long

[51] Stubbs MT, Oschkinat H, Mayr I, Huber R, Angliker H, Stone SR, Bode W (1992) The interaction of thrombin with fibrinogen. A structural basis for its specificity. European Journal of Biochemistry 206(1):187-195. https://doi.org/10.1111/j.1432-1033.1992.tb16916.x

[52] Ngaiza JR, Manley G, Grulich-Henn J, Krstenansky JL, Jaffe EA (1992) The fibrinogen anion-binding exosite of thrombin is necessary for induction of rises in intracellular calcium and prostacyclin production in endothelial cells. Journal of Cell Physiology 151(1):190-196. https://doi.org/10.1002/jcp.1041510124

[53] Sadler JE, Lentz SR, Sheehan JP, Tsiang M, Wu Q (1993) Structure-function relationships of the thrombin-thrombomodulin interaction. Haemostasis 23(Suppl 1):183-193. https://doi.org/10.1159/000216927

[54] Stubbs MT, Bode W (1993) A player of many parts: The spotlight falls on thrombin's structure. Thrombosis Research 69(1):1-58. https://doi.org/10.1016/0049-3848(93)90002-6

[55] Qiu X, Yin M, Padmanabhan KP, Krstenansky JL, Tulinsky A (1993) Structures of thrombin complexes with a designed and a natural exosite peptide inhibitor. Journal of Biological Chemistry 268(27):20318-20326. Available at http://www.jbc.org/content/268/27/20318.long

[56] Tulinsky A, Qiu X (1993) Active site and exosite binding of alpha-thrombin. Blood Coagulation and Fibrinolysis 4(2):305-312. https://doi.org/10.1097/00001721-199304000-00012

[57] Mathews II, Padmanabhan KP, Ganesh V, Tulinsky A, Ishii M, Chen J, Turck CW, Coughlin SR, Fenton JW 2nd (1994) Crystallographic structures of thrombin complexed with thrombin receptor peptides: Existence of expected and novel binding modes. Biochemistry 33(11):3266-3279. https://doi.org/10.1021/bi00177a018

[58] Wu Q, Picard V, Aiach M, Sadler JE (1994) Activation-induced exposure of the thrombin anion-binding exosite. Interactions of recombinant mutant prothrombins with thrombomodulin and a thrombin exosite-specific antibody. Journal of Biological Chemistry 269(5):3725-3730. Available at http://www.jbc.org/content/269/5/3725.long

[59] Blackhart BD, Cuenco G, Toda T, Scarborough RM, Wolf DL, Ramakrishnan V (1994) The anion-binding exosite is critical for the high affinity binding of thrombin to the human thrombin receptor. Growth Factors 11(1):17-28. https://doi.org/10.3109/08977199409015048

[60] Bouton MC, Jandrot-Perrus M, Moog S, Cazenave JP, Guillin MC, Lanza F (1995) Thrombin interaction with a recombinant Nterminal extracellular domain of the thrombin receptor in an acellular system. Biochemical Journal 305(Pt 2):635-641. https://doi.org/10.1042/bj3050635

[61] De Cristofaro R, De Candia E, Picozzi M, Landolfi R (1995) Conformational transitions linked to active site ligation in human thrombin: Effect on the interaction with fibrinogen and the cleavable platelet receptor. Journal of Molecular Biology 245(4):447458. https://doi.org/10.1006/jmbi.1994.0036

[62] Cheng Y, Slon-Usakiewicz JJ, Wang J, Purisima EO, Konishi Y (1996) Nonpolar interactions of thrombin and its inhibitors at the fibrinogen recognition exosite: Thermodynamic analysis. Biochemistry 35(40):13021-13029. https://doi.org/10.1021/bi961039c

[63] Jandrot-Perrus M, Bouton MC, Lanza F, Guillin MC (1996) Thrombin interaction with platelet membrane glycoprotein Ib. Seminars in Thrombosis and Hemostasis 22(2):151-156. https://doi.org/10.1055/s-2007-999003 
[64] Meh DA, Siebenlist KR, Mosesson MW (1996) Identification and characterization of the thrombin binding sites on fibrin. Journal of Biological Chemistry 271(38):23121-23125. https://doi.org/10.1074/jbc.271.38.23121

[65] Tulinsky A (1996) Molecular interactions of thrombin. Seminars in Thrombosis and Hemostasis 22(2):117-124. https://doi.org/10.1055/s-2007-998998

[66] Myles T, Church FC, Whinna HC, Monard D, Stone SR (1998) Role of thrombin anion-binding exosite-I in the formation of thrombin-serpin complexes. Journal of Biological Chemistry 273(47):31203-31208. https://doi.org/10.1074/jbc.273.47.31203

[67] Dharmawardana KR, Bock PE (1998) Demonstration of exosite I-dependent interactions of thrombin with human factor V and factor Va involving the factor Va heavy chain: Analysis by affinity chromatography employing a novel method for active-siteselective immobilization of serine proteinases. Biochemistry 37(38):13143-13152. https://doi.org/10.1021/bi9812165

[68] Becker DL, Fredenburgh JC, Stafford AR, Weitz JI (1999) Exosites 1 and 2 are essential for protection of fibrin-bound thrombin from heparin-catalyzed inhibition by antithrombin and heparin cofactor II. Journal of Biological Chemistry 274(10):6226-6233. https://doi.org/10.1074/jbc.274.10.6226

[69] Hogg PJ, Jackson CM, Labanowski JK, Bock PE (1996) Binding of fibrin monomer and heparin to thrombin in a ternary complex alters the environment of the thrombin catalytic site, reduces affinity for hirudin, and inhibits cleavage of fibrinogen. Journal of Biological Chemistry 271(42):26088-26095. https://doi.org/10.1074/jbc.271.42.26088

[70] Arocas V, Turk B, Bock SC, Olson ST, Björk I (2000) The region of antithrombin interacting with full-length heparin chains outside the high-affinity pentasaccharide sequence extends to Lys136 but not to Lys139. Biochemistry 39(29):8512-8518. https://doi.org/10.1021/bi9928243

[71] Arocas V, Bock SC, Olson ST, Bjork I (1999) The role of Arg46 and Arg47 of antithrombin in heparin binding. Biochemistry 38(31):10196-10204. https://doi.org/10.1021/bi990686b

[72] Ersdal-Badju E, Lu A, Zuo Y, Picard V, Bock SC (1997) Identification of the antithrombin III heparin binding site. Journal of Biological Chemistry 272(31):19393-19400. https://doi.org/10.1074/jbc.272.31.19393

[73] Bock PE, Olson ST, Bjork I (1997) Inactivation of thrombin by antithrombin is accompanied by inactivation of regulatory exosite I. Journal of Biological Chemistry 272(32):19837--19845. https://doi.org/10.1074/jbc.272.32.19837

[74] Olson ST, Bjork I, Shore JD (1993) Kinetic characterization of heparin-catalyzed and uncatalyzed inhibition of blood coagulation proteinases by antithrombin. Methods in Enzymology 222:525-559. https://doi.org/10.1016/0076-6879(93)22033-c

[75] Arni RK, Padmanabhan K, Padmanabhan KP, Wu TP, Tulinsky A (1994) Structure of the non-covalent complex of prothrombin kringle 2 with PPACK-thrombin. Chemistry and Physics of Lipids 67-68:59-66. https://doi.org/10.1016/0009-3084(94)90124-4

[76] Esmon CT, Jackson CM (1974) The conversion of prothrombin to thrombin. IV. The function of the fragment 2 region during activation in the presence of factor V. Journal of Biological Chemistry 249(24):7791-7797. Available at http://www.jbc.org/content/249/24/7791.long

[77] Jackson CM (2007) Models for reaction mechanisms in haemostasis - Contributions from the study of prothrombin activation. Thrombosis and Haemostasis 98(1):24-35. PMID: 17597986

[78] Mann KG (2010) Taking the thrombin "fork." Arteriosclerosis, Thrombosis, and Vascular Biology 30(7):1293-1299. https://doi.org/10.1161/ATVBAHA.108.179598

[79] Shi F, Hogg PJ, Winzor DJ, Jackson CM (1998) Evidence for multiple enzyme site involvement in the modulation of thrombin activity by products of prothrombin proteolysis. Biophysical Chemistry 75(3):187-199. https://doi.org/10.1016/s0301-4622(98)00205-1

[80] Sheehan JP, Sadler JE (1994) Molecular mapping of the heparin-binding exosite of thrombin. Proceedings of the National Academy of Sciences of the United States of America 91(12):5518-5522. https://doi.org/10.1073/pnas.91.12.5518

[81] Di Cera E, Guinto ER, Vindigni A, Dang QD, Ayala YM, Wuyi M, Tulinsky A (1995) The $\mathrm{Na}^{+}$binding site of thrombin. Journal of Biological Chemistry 270(38):22089-22092. https://doi.org/10.1074/jbc.270.38.22089

[82] Orthner CL, Kosow DP (1980) Evidence that human $\alpha$-thrombin is a monovalent cation-activated enzyme. Archives of Biochemistry and Biophysics 202(1):63-75. https://doi.org/10.1016/0003-9861(80)90406-3

[83] Wells CM, Di CE (1992) Thrombin is a Na(+)-activated enzyme. Biochemistry 31(47):11721-11730. https://doi.org/10.1021/bi00162a008

[84] Esmon CT (2003) The protein C pathway. Chest 124(3 Suppl):26S-32S. https://doi.org/10.1378/chest.124.3_suppl.26s

[85] Suzuki K, Stenflo J, Dahlbäck B, Teodorsson B (1983) Inactivation of human coagulation factor V by activated protein C. Journal of Biological Chemistry 258(3):1914-1920. Available at http://www.jbc.org/content/258/3/1914.long

[86] Pineda AO, Carrell CJ, Bush LA, Prasad S, Caccia S, Chen ZW, Mathews FS, Di Cera E (2004) Molecular dissection of Na+ binding to thrombin. Journal of Biological Chemistry 279(30):31842-31853. https://doi.org/10.1074/jbc.M401756200

[87] Di Cera E (2006) A structural perspective on enzymes activated by monovalent cations. Journal of Biological Chemistry 281(3):1305-1308. https://doi.org/10.1074/jbc.R500023200

[88] Pineda AO, Chen ZW, Bah A, Garvey LC, Mathews FS, Di Cera E (2006) Crystal structure of thrombin in a self-inhibited conformation. Journal of Biological Chemistry 281(43):32922-32928. https://doi.org/10.1074/jbc.M605530200

[89] Angliker H, Shaw E, Stone SR (1993) Synthesis of oligopeptide chloromethanes to investigate extended binding regions of proteinases: Application to the interaction of fibrinogen with thrombin. Biochemical Journal 292(Pt 1):261-266. https://doi.org/10.1042/bj2920261

[90] Binnie CG, Lord ST (1993) The fibrinogen sequences that interact with thrombin. Blood 81(12):3186-3192. https://doi.org/10.1182/blood.V81.12.3186.3186

[91] Jackson CM, Esnouf MP (2005) Has the time arrived to replace the quick prothrombin time test for monitoring oral anticoagulant therapy? Clinical Chemistry 51(3):483-485. https://doi.org/10.1373/clinchem.2004.045393 
[92] Luchtman-Jones L, Broze GJ Jr (1995) The current status of coagulation. Annals of Medicine 27(1):47-52. https://doi.org/10.3109/07853899509031935

[93] von dem Borne PA, Meijers JC, Bouma BN (1996) Effect of heparin on the activation of factor XI by fibrin-bound thrombin. Thrombosis and Haemostasis 76(3):347-353. https://doi.org/10.1055/s-0038-1650582

[94] Ayala YM, Cantwell AM, Rose T, Bush LA, Arosio D, Di Cera E (2001) Molecular mapping of thrombin-receptor interactions. Proteins 45(2):107-116. https://doi.org/10.1002/prot.1130

[95] Coughlin SR (2005) Protease-activated receptors in hemostasis, thrombosis and vascular biology. Journal of Thrombosis and Haemostasis 3(8):1800-1814. https://doi.org/10.1111/j.1538-7836.2005.01377.x

[96] Vu T-KH, Wheaton VI, Hung DT, Charo I, Coughlin SR (1991) Domains specifying thrombin-receptor interaction. Nature 353:674677. https://doi.org/10.1038/353674a0

[97] Doyle MF, Mann KG (1990) Multiple active forms of thrombin. IV. Relative activities of meizothrombins. Journal of Biological Chemistry 265(18):10693-10701. Available at http://www.jbc.org/content/265/18/10693.long

[98] Owen WG, Jackson CM (1973) Activation of prothrombin with Oxyuranus scutellatus scutellatus (Taipan snake) venom. Thrombosis Research 3:704-714. https://doi.org/10.1016/0049-3848(73)90017-0

[99] Walker FJ, Owen WG, Esmon CT (1980) Characterization of the prothrombin activator from the venom of Oxyuranus scutellatus scutellatus (Taipan venom). Biochemistry 19:1020-1023. https://doi.org/10.1021/bi00546a029

[100]Briet E, Noyes CM, Roberts HR, Griffith MJ (1982) Cleavage and activation of human prothrombin by Echis carinatus venom. Thrombosis Research 27(5):591-600. https://doi.org/10.1016/0049-3848(82)90306-1

[101] Kornalik F, Blomback B (1975) Prothrombin activation induced by Echarin-a prothrombin converting enzyme from Echis carinatus venom. Thrombosis Research 6:53-63. https://doi.org/10.1016/0049-3848(75)90150-4

[102] Guillin MC, Bezeaud A (1981) Characterization of a variant of human prothrombin: Prothrombin Madrid. Annals of the New York Academy of Sciences 370:414-425. https://doi.org/10.1111/j.1749-6632.1981.tb29753.x

[103]Bezeaud A, Drouet L, Soria C, Guillin MC (1984) Prothrombin Salakta: An abnormal prothrombin characterized by a defect in the active site of thrombin. Thrombosis Research 34(6):507-518. https://doi.org/10.1016/0049-3848(84)90255-x

[104]Esmon CT, Owen WG, Jackson CM (1974) A plausible mechanism for prothrombin activation by factor Xa, factor Va, phospholipid, and calcium ions. Journal of Biological Chemistry 249(24):8045-8047. Available at http://www.jbc.org/content/249/24/8045.long

[105]Braun PJ, Hofsteenge J, Chang J-Y, Stone SR (1988) Preparation and characterization of proteolyzed forms of human $\alpha$-thrombin. Thrombosis Research 50(2):273-283. https://doi.org/10.1016/0049-3848(88)90228-9

[106]Lottenberg R, Hall JA, Fenton JW 2nd, Jackson CM (1982) The action of thrombin on peptide p-nitroanilide substrates: Hydrolysis of Tos-Gly-Pro-Arg-pNA and D-Phe-Pip-Arg-pNA by human $\alpha$ and $\gamma$ and bovine $\alpha$ and $\beta$-thrombins. Thrombosis Research 28(3):313-332. https://doi.org/10.1016/0049-3848(82)90114-1

[107]Lewis SD, Lorand L, Fenton JW 2nd, Shafer JA (1987) Catalytic competence of human alpha- and gamma-thrombin in the activation of fibrinogen and factor XIII. Biochemistry 26(24):7597-7603. https://doi.org/10.1021/bi00398a010

[108]Latallo ZS, Jackson CM (1986) Reaction of thrombins with human antithrombin III: II. Dependence of rate of inhibition on molecular form and origin of thrombin. Thrombosis Research 43(5):523-537. https://doi.org/10.1016/0049-3848(86)90072-1'

[109]Chang J-Y (1986) The structures and proteolytic specificities of autolysed human thrombin. Biochemical Journal 240(3):797-802. https://doi.org/10.1042/bj2400797

[110]Rydel TJ, Yin M, Padmanabhan KP, Blankenship DT, Cardin AD, Correa PE, Fenton JW 2nd, Tulinsky A (1994) Crystallographic structure of human gamma-thrombin. Journal of Biological Chemistry 269(35):22000-22006. http://www.jbc.org/content/269/35/22000.long

[111]Witting JI, Miller TM, Fenton JW 2nd (1987) Human $\alpha$ - and $\gamma$-thrombin specificity with tripeptide p-nitroanalide substrates under physiologically relevant conditions. Thrombosis Research 46(4):567-574. https://doi.org/10.1016/0049-3848(87)90157-5

[112] Gaffney PJ, Miller-Andersson M, Kirkwood TB (1978) Unreliability of chromogenic substrates for assay of the clotting activity of thrombin. Haemostasis 7(2-3):109-112. https://doi.org/10.1159/000214246

[113]Elion J, Boissel JP, Le Bonniec B, Bezeaud A, Jandrot-Perrus M, Rabiet MJ, Guillin MC (1986) Proteolytic derivatives of thrombin. Annals of the New York Academy of Sciences 485:16-26. https://doi.org/10.1111/j.1749-6632.1986.tb34564.x

[114] Ascenzi P, Menegatti E, Bolognesi M, Guarneri M, Amiconi G (1986) Catalytic properties of bovine alpha-thrombin: A comparative steady-state and pre-steady-state study. Biochimica et Biophysica Acta 871:319-323. https://doi.org/10.1016/0167-4838(86)90215-3

[115] Ascenzi P, Amiconi G, Coletta M, Lupidi G, Menegatti E, Onesti S, Bolognesi M (1992) Binding of hirudin to human alpha, beta and gamma-thrombin. A comparative kinetic and thermodynamic study. Journal of Molecular Biology 225(1):177-184. https://doi.org/10.1016/0022-2836(92)90904-x

[116]Fenton JW 2nd, Fasco MJ, Stackrow AB (1977) Human thrombins. Production, evaluation, and properties of alpha-thrombin. Journal of Biological Chemistry 252(11):3587-3598. Available at http://www.jbc.org/content/252/11/3587.long

[117]Fenton JW 2nd, Campbell WP, Harrington JC, Miller KD (1971) Large-scale preparation and preliminary characterization of human thrombin. Biochimica et Biophysica Acta 229(1):26-32. https://doi.org/10.1016/0005-2795(71)90313-8

[118]Kekwick RA, Mackay ME, Record BR (1946) Fractionation of human plasma with ether. Nature 157:629. https://doi.org/10.1038/157629a0

[119]Bajaj SP, Mann KG (1973) Simultaneous purification of bovine prothrombin and factor X. Activation of prothrombin by trypsinactivated factor X. Journal of Biological Chemistry 248(22):7729-7741. Available at http://www.jbc.org/content/248/22/7729.long

[120]Miller GJ, Stirling Y, Esnouf MP, Heinrich J, van de Loo J, Kienast J, Wu KK, Morrissey JH, Meade TW, Martin JC, Imeson JD, Cooper JA, Finch A (1994) Factor VII-deficient substrate plasmas depleted of protein C raise the sensitivity of the factor VII bio- 
assay to activated factor VII: An international study. Thrombosis and Haemostasis 71(1):38-48. https://doi.org/10.1055/s-0038-1642382

[121] Jackson CM, Johnson TF, Hanahan DJ (1968) Studies on bovine factor X. I. Large-scale purification of the bovine plasma protein possessing factor X activity. Biochemistry 7(12):4492-4505. https://doi.org/10.1021/bi00852a046

[122] Owen WG, Esmon CT, Jackson CM (1974) The conversion of prothrombin to thrombin. I. Characterization of the reaction products formed during the activation of bovine prothrombin. Journal of Biological Chemistry 249(2):594-605. https://doi.org/10.1021/bi00852a046

[123]Mann KG (1976) Prothrombin. Methods in Enzymology 45:123-156. https://doi.org/10.1016/s0076-6879(76)45016-4

[124] Seegers WH (1962) Prothrombin (published for the Commonwealth Fund by Harvard University Press, Cambridge, MA), 728 p.

[125]Dahlbäck B (1983) Purification of human vitamin K-dependent protein S and its limited proteolysis by thrombin. Biochemical Journal 209(3):837-846. https://doi.org/10.1042/bj2090837

[126]Hogg PJ, Stenflo J (1991) Interaction of human protein $Z$ with thrombin: Evaluation of the species difference in the interaction between bovine and human protein $\mathrm{Z}$ and thrombin. Biochemical and Biophysical Research Communications 178:801-807. https://doi.org/10.1016/0006-291x(91)90962-7

[127] Stenflo J (1976) A new vitamin K-dependent protein. Purification from bovine plasma and preliminary characterization. Journal of Biological Chemistry 251(2):355-363. Available at http://www.jbc.org/content/251/2/355.long

[128]Stenflo J (1984) Structure and function of protein C. Seminars in Thrombosis and Hemostasis 10(2):109-121. https://doi.org/10.1055/s-2007-1004413

[129]Prowse CV, Esnouf MP (1977) The isolation of a new warfarin-sensitive protein from bovine plasma. Biochemical Society Transactions 5(1):255-256. https://doi.org/10.1042/bst0050255

[130]Lanchantin GF (1958) An analysis of human prothrombin by starch block electrophoresis. American Journal of Physiology 194(1):7-15. https://doi.org/10.1152/ajplegacy.1958.194.1.7

[131]Lanchantin GF, Friedmann JA, Degroot J, Mehl JW (1963) Preparation of human plasma prothrombin and some of its sedimentation properties. Journal of Biological Chemistry 238:238-243. Available at http://www.jbc.org/content/238/1/238.long

[132] Ichinose A, Takeya H, Espling E, Iwanaga S, Kisiel W, Davie EW (1990) Amino acid sequence of human protein Z, a vitamin Kdependent plasma glycoprotein. Biochemical and Biophysical Research Communications 172(3):1139-1144. https://doi.org/10.1016/0006-291x(90)91566-b

[133]DiScipio RG, Davie EW (1979) Characterization of protein S, a gamma-carboxyglutamic acid containing protein from bovine and human plasma. Biochemistry 18(5):899-904. https://doi.org/10.1021/bi00572a026

[134] Tishkoff GH, Williams LC, Brown DM (1968) Preparation of highly purified prothrombin complex: I. Crystallization, biological activity, and molecular properties. Journal of Biological Chemistry 243:4151-4167. Available at http://www.jbc.org/content/243/15/4151.long

[135] Tishkoff GH, Williams LC, Brown DM (1970) Preparation and properties of human prothrombin complex. Thrombosis and Haemostasis 24:326-333. https://doi.org/10.1055/s-0038-1654240

[136] Seegers WH (1981) A personal perspective on hemostasis and thrombosis (1937-1981). Seminars in Thrombosis and Hemostasis 7(3-4):177-307. PMID: 7034202

[137] Ornstein L (1964) Disc electrophoresis. I. Background and theory. Annals of the New York Academy of Sciences 121:321-349. https://doi.org/10.1111/j.1749-6632.1964.tb14207.x

[138]Laemmli UK (1970) Cleavage of structural proteins during the assembly of the head of bacteriophage T4. Nature 227(5259):680685. https://doi.org/10.1038/227680a0

[139]Esnouf MP, Williams WJ (1962) The isolation and purification of a bovine-plasma protein which is a substrate for the coagulant fraction of Russell's-viper venom. Biochemical Journal 84:62-71. https://doi.org/10.1042/bj0840062

[140]Robertson I, Gaffney PJ, Bangham DR (1975) Standard for human thrombin. Thrombosis et Diathesis and Haemorrhagica 34(1):318. https://doi.org/10.1055/s-0038-1651441

[141] Gaffney PJ, Edgell TA (1995) The International and "NIH" units for thrombin-How do they compare? Thrombosis and Haemostasis 74(3):900-903. https://doi.org/10.1055/s-0038-1649844

[142]Kisiel W, Davie EW (1975) Isolation and characterization of bovine factor VII. Biochemistry 14(22):4928-4934. https://doi.org/10.1021/bi00693a023

[143] Miletich J, Broze G, Majerus P (1981) Purification of human coagulation factors II, IX and X using sulfated dextran beads. Methods in Enzymology 80:221-228. https://doi.org/10.1016/S0076-6879(81)80020-1

[144]Bock PE (1992) Active-site-selective labeling of blood coagulation proteinases with fluorescence probes by the use of thioester peptide chloromethyl ketones. II. Properties of thrombin derivatives as reporters of prothrombin fragment 2 binding and specificity of the labeling approach for other proteinases. Journal of Biological Chemistry 267(21):14974-14981. Available at https://www.jbc.org/content/267/21/14974

[145] Horne MK 3rd, Gralnick HR (1984) The oligosaccharide of human thrombin: Investigations of functional significance. Blood 63(1):188-194. https://doi.org/10.1182/blood.V63.1.188.188

[146]Nilsson B, Horne MK 3rd, Gralnick HR (1983) The carbohydrate of human thrombin: Structural analysis of glycoprotein oligosaccharides by mass spectrometry. Archives in Biochemistry and Biophysics 224(1):127-133. https://doi.org/10.1016/0003-9861(83)90196-0

[147]Mizuochi T, Fujii J, Kisiel W, Kobata A (1981) Studies on the structures of the carbohydrate moiety of human prothrombin. Journal of Biochemistry 90(4):1023-1031. https://doi.org/10.1093/oxfordjournals.jbchem.a133554 
[148]Henriksen A, Christensen TB, Helgeland L (1976) On the significance of the carbohydrate moieties of bovine prothrombin for clotting activity. Biochimica et Biophysica Acta 421:348-352. https://doi.org/10.1016/0304-4165(76)90301-9

[149] Skaug K, Christensen TB (1971) The significance of the carbohydrate constituents of bovine thrombin for the clotting activity. Biochimica et Biophysica Acta 230(3):627-629. https://doi.org/10.1016/0304-4165(71)90197-8

[150]Bajaj SP, Rapaport SI, Prodonos C, Russell WA (1981) Heterogeneity in human prothrombin: Analysis of cause. Blood 58(5):886891. https://doi.org/10.1182/blood.V58.5.886.886

[151] Shuman MA, Majerus PW (1976) The measurement of thrombin in clotting blood by radioimmunoassay. Journal of Clinical Investigation 58(5):1249-1258. https://doi.org/10.1172/JCI108579

[152] Higgins DL, Lewis SD, Shafer JA (1983) Steady state kinetic parameters for the thrombin-catalyzed conversion of human fibrinogen to fibrin. Journal of Biological Chemistry 258(15):9276-9282. Available at http://www.jbc.org/content/258/15/9276.long

[153] Higgins DL, Lewis SD, Penner JA, Shafer JA (1982) A kinetic method for characterization of heterogenous fibrinogen and its application to fibrinogen Grand Rapids, a congenital dysfibrinogenemia. Thrombosis and Haemostasis 48(2):182-186. https://doi.org/10.1055/s-0038-1657252

[154]Lewis SD, Shafer JA (1984) A thrombin assay based upon the release of fibrinopeptide A from fibrinogen: Definition of a new thrombin unit. Thrombosis Research 35(2):111-120. https://doi.org/10.1016/0049-3848(84)90206-8

[155]De Cristofaro R, Di Cera E (1992) Modulation of thrombin-fibrinogen interaction by specific ion effects. Biochemistry 31(1):257265. https://doi.org/10.1021/bi00116a035

[156]Mihalyi E (1988) Clotting of bovine fibrinogen. Calcium binding to fibrin during clotting and its dependence on release of fibrinopeptide B. Biochemistry 27(3):967-976. https://doi.org/10.1021/bi00403a020

[157]Binnie CG, Hettasch JM, Strickland E, Lord ST (1993) Characterization of purified recombinant fibrinogen: Partial phosphorylation of fibrinopeptide A. Biochemistry 32(1):107-113. https://doi.org/10.1021/bi00052a015

[158]Ebert RF, Bell WR (1985) Assay of human fibrinopeptides by high-performance liquid chromatography. Analytical Biochemistry 148(1):70-78. https://doi.org/10.1016/0003-2697(85)90629-3

[159] Hanna LS, Scheraga HA, Francis CW, Marder VJ (1984) Comparison of structures of various human fibrinogens and a derivative thereof by a study of the kinetics of release of fibrinopeptides. Biochemistry 23(20):4681-4687. https://doi.org/10.1021/bi00315a025

[160] Southan C, Thompson E, Lane DA (1986) Direct analysis of plasma fibrinogen-derived fibrinopeptides by high-performance liquid chromatography. Thrombosis Research 43(2):195-204. https://doi.org/10.1016/0049-3848(86)90060-5

[161]Kollman JM, Pandi L, Sawaya MR, Riley M, Doolittle RF (2009) Crystal structure of human fibrinogen. Biochemistry 48(18):38773886. https://doi.org/10.1021/bi802205g

[162] Brown JH, Volkmann N, Jun G, Henschen-Edman AH, Cohen C (2000). The crystal structure of modified bovine fibrinogen. Proceedings of the National Academy of Sciences of the United States of America 97(1):85-90. https://doi.org/10.1073/pnas.97.1.85

[163]Lewis SD, Shields PP, Shafer JA (1985) Characterization of the kinetic pathway for liberation of fibrinopeptides during assembly of fibrin. Journal of Biological Chemistry 260(18):10192-10199. http://www.jbc.org/content/260/18/10192.long

[164]Ng AS, Lewis SD, Shafer JA (1993) Quantifying thrombin-catalyzed release of fibrinopeptides from fibrinogen using highperformance liquid chromatography. Methods in Enzymology 222:341-358. https://doi.org/10.1016/0076-6879(93)22023-9

[165] Vindigni A, Di Cera E (1996) Release of fibrinopeptides by the slow and fast forms of thrombin. Biochemistry 35(14):4417-4426. https://doi.org/10.1021/bi952834d

[166]Laudano AP, Doolittle RF (1978) Synthetic peptide derivatives that bind to fibrinogen and prevent the polymerization of fibrin monomers. Proceedings of the National Academy of Sciences of the United States of America 75:3085-3089. https://doi.org/10.1073/pnas.75.7.3085

[167] Strong DD, Laudano AP, Hawiger J, Doolittle RF (1982) Isolation, characterization, and synthesis of peptides from human fibrinogen that block the staphylococcal clumping reaction and construction of a synthetic clumping particle. Biochemistry 21(6):1414-1420. https://doi.org/10.1021/bi00535a048

[168] Shafer JA, Lewis SD, Janus TJ, Lorand L (1986) Effect of fibrinogen and $\mathrm{Ca}^{2+}$ on the thrombin-catalyzed proteolytic event that triggers activation of factor XIII. Annals of the New York Academy of Sciences 485:134-139. https://doi.org/10.1111/j.1749-6632.1986.tb34575.x

[169]Lottenberg R, Hall JA, Blinder M, Binder EP, Jackson CM (1983) The action of thrombin on peptide p-nitroanilide substrates. Substrate selectivity and examination of hydrolysis under different reaction conditions. Biochimica et Biophysica Acta 742(3):539557. https://doi.org/10.1016/0167-4838(83)90272-8

[170] Wasiewski W, Fasco MJ, Martin BM, Detwiler TC, Fenton JW 2nd (1976) Thrombin adsorption to surfaces and prevention with polyethylene glycol 6,000. Thrombosis Research 8(6):881-886. https://doi.org/10.1016/0049-3848(76)90017-7

[171]Latallo ZS, Hall JA (1986) Reaction of thrombins with human antithrombin III. I. Enzyme activity losses unrelated to the inhibitory reaction and their prevention. Thrombosis Research 43(5):507-521. https://doi.org/10.1016/0049-3848(86)90071-x

[172]Hoofnagle AN, Whiteaker JR, Carr SA, Kuhn E, Liu T, Massoni SA, Thomas SN, Townsend RR, Zimmerman LJ, Boja E, Chen J, Crimmins DL, Davies SR, Gao Y, Hiltke TR, Ketchum KA, Kinsinger CR, Mesri M, Meyer MR, Qian W-J, Schoenherr RM, Scott MG, Shi T, Whiteley GR, Wrobel JA, Wu C, Ackermann BL, Aebersold R, Barnidge DR, Bunk DM, Clarke N, Fishman JB, Grant RP, Kusebauch U, Kushnir MM, Lowenthal MS, Moritz RL, Neubert H, Patterson SD, Rockwood AL, Rogers J, Singh RJ, Van Eyk JE, Wong SH, Zhang S, Chan DW, Chen X, Ellis MJ, Liebler DC, Rodland KD, Rodriguez H, Smith RD, Zhang Z, Zhang H, Paulovich AG (2016) Recommendations for the generation, quantification, storage, and handling of peptides used for mass spectrometry-based assays. Clinical Chemistry 62(1):48-69. https://doi.org/10.1373/clinchem.2015.250563

[173] Siekmann L (2009) Implementation of the concept of traceability in laboratory medicine in external quality assessment. Clinical Biochemistry 42(4-5):293-294. https://doi.org/10.1016/j.clinbiochem.2008.09.014 
[174]BIPM (2019) The International System of Units (SI) (International Bureau of Weights and Measures [BIPM], Saint-Cloud, France), 9th Ed. Available at https://www.bipm.org/utils/common/pdf/si-brochure/SI-Brochure-9-EN.pdf

See also: Newell DB, Tiesinga E, Eds (2019) The International System of Units (SI) (National Institute of Standards and Technology, Gaithersburg, MD), 2019 Edition, Special Publication 330. https://doi.org/10.6028/NIST.SP.330-2019

[175]Hager K, Felicetti M, Seefried G, Platt D (1994) Fibrinogen and aging. Aging (Milano) 6(2):133-138. https://doi.org/10.1007/bf03324226

[176]Chantarangkul V, Tripodi A, Mannucci PM (1994) Results of a collaborative study for fibrinogen measurement. Evidence that the use of a common calibrator improves interlaboratory agreement. Blood Coagulation and Fibrinolysis 5(5):761-766. https://doi.org/10.1097/00001721-199410000-00013

[177]Clauss A (1957) Gerinnungsphysiologische Schnellmethode zur Bestimmung des Fibrinogens. Acta Haematologica 17:237. https://doi.org/10.1159/000205234

[178]De Cristofaro R, Di Cera E (1990) Effect of protons on the amidase activity of human $\alpha$-thrombin. Analysis in terms of a general linkage scheme. Journal of Molecular Biology 216:1077-1085. https://doi.org/10.1016/s0022-2836(99)80021-7

[179] Mihalyi E (1970) Hydrogen ion titration curves of the native bovine fibrinogen and of bovine fibrinogen denature of $5 \mathrm{M}$ guanidine hydrochloride. Biochemistry 9(4):804-816. https://doi.org/10.1021/bi00806a013

[180]Di Cera E, De Cristofaro R, Albright DJ, Fenton JW 2nd (1991) Linkage between proton binding and amidase activity in human $\alpha-$ thrombin: Effect of ions and temperature. Biochemistry 30:7913-7924. https://doi.org/10.1021/bi00246a007

[181]Lottenberg R, Jackson CM (1983) Solution composition dependent variation in extinction coefficients for p-nitroaniline. Biochimica et Biophysica Acta 742(3):558-564. https://doi.org/10.1016/0167-4838(83)90273-x

[182]Di Cera E, Dang QD, Ayala YM (1997) Molecular mechanisms of thrombin function. Cellular and Molular Life Sciences 53(9):701-730. https://doi.org/10.1007/s000180050091

[183]Brezniak DV, Hassouna HI, Fenton JW 2nd (1994) High stability of dilute human alpha-thrombin in salt solutions. Blood Coagulation and Fibrinolysis 5(5):847-848. https://doi.org/10.1097/00001721-199410000-00027

[184]Landis BH, Koehler KA, Fenton JW 2nd (1981) Human thrombins. Group IA and IIA salt-dependent properties of alpha-thrombin. Journal of Biological Chemistry 256(9):4604-4610. http://www.jbc.org/content/256/9/4604.long

[185] Janus TJ, Lewis SD, Lorand L, Shafer JA (1983) Promotion of thrombin-catalyzed activation of factor XIII by fibrinogen. Biochemistry 22(26):6269-6272. https://doi.org/10.1021/bi00295a035

[186]Naski MC, Lorand L, Shafer JA (1991) Characterization of the kinetic pathway for fibrin promotion of alpha-thrombin-catalyzed activation of plasma factor XIII. Biochemistry 30(4):934-941. https://doi.org/10.1021/bi00218a008

[187]Lewis SD, Janus TJ, Lorand L, Shafer JA (1985) Regulation of formation of factor XIIIa by its fibrin substrates. Biochemistry 24(24):6772-6777. https://doi.org/10.1021/bi00345a007

[188]Donovan JW, Mihalyi E (1985) Clotting of fibrinogen. 1. Scanning calorimetric study of the effect of calcium. Biochemistry 24(14):3434-3443. https://doi.org/10.1021/bi00335a007

[189] Mihalyi E (2004) Review of some unusual effects of calcium binding to fibrinogen. Biophysical Chemistry 112(2-3):131-140. https://doi.org/10.1016/j.bpc.2004.07.012

[190]Bode W, Stubbs MT (1993) Spatial structure of thrombin as a guide to its multiple sites of interaction. Seminars in Thrombosis and Hemostasis 19(4):321-333. https://doi.org/10.1055/s-2007-993283

[191] Mann KG, Jenny RJ, Krishnaswamy S (1988) Cofactor proteins in the assembly and expression of blood clotting enzyme complexes. Annual Review of Biochemistry 57:915-956. https://doi.org/10.1146/annurev.bi.57.070188.004411

[192] Mosesson MW (2005) Fibrinogen and fibrin structure and functions. Journal of Thrombosis and Haemostasis 3(8):1894-1904. https://doi.org/10.1111/j.1538-7836.2005.01365.x

[193]Badellino KO, Walsh PN (2001) Localization of a heparin binding site in the catalytic domain of factor XIa. Biochemistry 40(25):7569-7580. https://doi.org/10.1021/bi0027433

[194]Bouma BN, von dem Borne PAK, Meijers JCM (2006) Discovery of thrombin activatable fibrinolysis inhibitor (TAFI). Journal of Thrombosis and Haemostasis 4(1):257-258. https://doi.org/10.1111/j.1538-7836.2005.01666.x

[195]Tollefsen DM (1997) Heparin cofactor II. Advances in Experimental Medicine and Biology 425:35-44. https://doi.org/10.1007/978-1-4615-5391-5_4

[196] Stief TW (2013) Clinical biochemistry of thrombin. Hemostasis Laboratory 6:1-11.

[197]Uriano GA, Cali JP (1977) Role of reference materials and reference methods in the measurement process. Validation of the Measurement Process, ed De Voe JR (American Chemical Society, Washington, D.C.) pp 140-161. https://doi.org/10.1021/bk-1977-0063.ch004

[198] Siekmann L (2013) Metrological traceability_A concept for standardization in laboratory medicine. Clinical Chemistry and Laboratory Medicine 51(5):953-957. https://doi.org/10.1515/cclm-2012-0710

[199]IPCC (2007) IPCC Fourth Assessment Report: Climate Change 2007: Synthesis Report. Contribution of Working Groups I, II and III to the Fourth Assessment Report of the Intergovernmental Panel on Climate Change (Intergovernmental Panel on Climate Change, Geneva, Switzerland). Available at https://www.ipcc.ch/report/ar4/syr/

[200]Duewer DL (2014) Metrology for identity and other nominal properties. Standards for Pathogen Identification via Next-Generation Sequencing Workshop (National Institute of Standards and Technology, Gaithersburg, MD), 20-21 October 2014. Available at https://www.slideshare.net/nist-spin/spin-duewer-20141017 


\title{
Journal of Research of the National Institute of Standards and Technology
}

\begin{abstract}
About the authors: Craig M. Jackson, retired, was formerly a professor of biological chemistry and associate professor of internal medicine at Washington University School of Medicine, St. Louis, MO, and he is a Fellow of the American Association for the Advancement of Science and Fellow of the National Academy of Clinical Biochemistry. His address is 5931 Seacrest View Rd., San Diego, CA 92121, USA.

M. Peter Esnouf, retired, was formerly a member of the Nuffield Department of Clinical Biochemistry, University of Oxford, Radcliffe Infirmary, Oxford, OX2 6HE, United Kingdom.

David L. Duewer is a research chemist in the Chemical Sciences Division at NIST. The National Institute of Standards and Technology is an agency of the U.S. Department of Commerce.
\end{abstract}

